\title{
Piezoelectric Materials for Tissue Regeneration: A Review
}

Amir Hossein Rajabi, Michael Jaffe, Treena Livingston Arinzeh*

Department of Biomedical Engineering, New Jersey Institute of Technology, Newark, NJ 07102-

$$
\text { 1982, USA }
$$

*Corresponding Author:

Treena Livingston Arinzeh, $\mathrm{PhD}$

Professor

Biomedical Engineering

New Jersey Institute of Technology

323 Martin Luther King Blvd.

Newark, NJ 07102

973-596-5269 (voice)

973-596-5222 (fax)

arinzeh@njit.edu 


\begin{abstract}
The discovery of piezoelectricity, endogenous electric fields and transmembrane potentials in biological tissues raised the question whether or not electric fields play an important role in cell function. It has kindled research and the development of technologies in emulating biological electricity for tissue regeneration. Promising effects of electrical stimulation on cell growth and differentiation and tissue growth has led to interest in using piezoelectric scaffolds for tissue repair. Piezoelectric materials can generate electrical activity when deformed. Hence, an external source to apply electrical stimulation or implantation of electrodes is not needed. Various piezoelectric materials have been employed for different tissue repair applications, particularly in bone repair, where charges induced by mechanical stress can enhance bone formation; and in neural tissue engineering, in which electric pulses can stimulate neurite directional outgrowth to fill gaps in nervous tissue injuries. In this review, a summary of piezoelectricity in different biological tissues, mechanisms through which electrical stimulation may affect cellular response, and recent advances in the fabrication and application of piezoelectric scaffolds will be discussed.
\end{abstract}

Keywords: piezoelectric; electrical stimulation; tissue engineering; tissue regeneration; scaffolds 


\section{Introduction}

Piezoelectric materials are smart materials that can generate electrical activity in response to minute deformations. First discovered by Pierre and Jacques Curie in 1880[1], deformation results in the asymmetric shift of ions or charges in piezoelectric materials, which induces a change in the electric polarization, and thus electricity is generated. Piezoelectric materials are widely used in various electronic applications such as transducers, sensors and actuators. For biomedical applications, piezoelectric materials allow for the delivery of an electrical stimulus without the need for an external power source. As a scaffold for tissue engineering, there is growing interest in piezoelectric materials due to their potential of providing electrical stimulation to cells to promote tissue formation. In this review, we cover the discovery of piezoelectricity in biological tissues, its connection to streaming potentials, biological response to electrical stimulation and commonly used piezoelectric materials for tissue regeneration. This review summarizes their potential as a promising scaffold in the tissue engineering field.

\section{Piezoelectricity in Biological Tissues}

In 1940, Martin[2] noticed the first demonstration of biological piezoelectricity, when he detected electric potentials from a bundle of wool encapsulated in shellac while compressed by two brass plates. The main constituent of mammalian hair, wool, horn and hoof is $\alpha$-keratin[3, 4], which has a spiral $\alpha$-helix structure[4]. The piezoelectricity of such tissues is attributed to the compact alignment of these highly ordered $\alpha$-helices and their inherent polarization[5, 6]. $\alpha$-helix is a right handed coil stabilized by the hydrogen bonds between the hydrogen of one amine group with the oxygen of a consecutive carbonyl group. As demonstrated in Figure 1, the helical 
structure repeatedly aligns the dipoles of the backbone amino acids and causes a significant permanent polarization $[7,8]$.

Yasuda[9] reported the piezoelectricity of bone in 1954. Later, Yasuda and Fukada[10] observed piezoelectricity in boiled bone and consequently concluded that living cells were not responsible for the piezoelectric response. They attributed the piezoelectric behavior of bone to the application of shear on collagen. Bone is a composite of densely packed aligned collagen fibrils containing hydroxyapatite particles[11]. Collagen as the most abundant mammalian protein, also has a spiral structure consisting of three helices, called triple helix[12]. Piezoforce microscopy (PFM) is a modification of atomic force microscopy (AFM), which has been recently used to study the piezoelectricity of nanomaterials. An AC bias between the conductive AFM tip and the substrate beneath the sample applies an electric field through the sample, causing a deformation in the piezoelectric material. The contacting AFM tip detects the deformation, which is subsequently translated to the amplitude of the piezoresponse[13]. PFM can be performed in vertical or lateral modes; vertical deflection of the AFM tip manifests normal deformation of the material. In lateral mode, torsion of the AFM tip reveals shear deformation of the domain[14].

The piezoelectricity of single collagen fibrils has been studied using piezoforce microscopy $[15$, 16]. PFM images of collagen fibrils show lateral piezoresponse along the fibril axis and negligible vertical and radial piezoresponse, revealing the unidirectional polarization along the collagen fibril axis[15]. Figure 2 demonstrates the topography of a single collagen fibril imaged by AFM, and its corresponding shear piezoelectricity imaged by lateral PFM, demonstrating the periodicity of the piezoforce amplitude attributed to the gaps and overlaps in the quarterstaggered structure of collagen[16]. 
For years, it was believed that since hydroxyapatite crystalizes in a centrosymmetric space group in the hexagonal system[17], it could not be piezoelectric[18]. However, computational studies reported a lack of an inversion center in hydroxyapatite that could theoretically suggest possible piezoelectricity of this crystal[19]. Tofail et al.[20] have demonstrated the piezoelectricity of sintered hydroxyapatite using PFM, which suggests that alongside collagen, hydroxyapatite may also contribute to the piezoelectricity of bone. Piezoelectricity of other collagenous tissues such as tendon[21-23], dentin[24], cementum[25] and cartilage[26, 27] have also been reported. Polysaccharides such as wood[28] and chitin[29] as well as polynucleotides such as deoxyribonucleic acid (DNA) have also revealed piezoelectric response[30].

\section{Piezoelectricity and Streaming Potential}

In 1892, Julius Wolff[31] suggested that bone remodels its architecture in response to stress. "Wolff's Law" manifests itself in the denser bone in tennis players' racket-holding arms or bone loss in astronauts. After the discovery of piezoresponse in dry bone[9], the proposed mechanism to describe bone growth and resorption in response to stress was piezoelectricity. As one of the pioneers of investigating the biological effects of piezoelectricity, Bassett[32] observed that unlike undeformed samples, periodically deformed cultivated chick embryonic tibiae produced large periosteal chondroid masses after 7 days, and described Wolff's law as a negative feedback loop: applied load on bone causes strain in less dense regions; while denser and consequently stiffer regions remain unstrained. The strain is transformed into an electric field that aggregates and aligns macromolecules and ions in the extracellular matrix, which stimulates cells to remodel the bone architecture until the signal is switched off. As piezoelectric 
measurements expanded to wet bone[33] and wet collagen[34], which is hydrated bone and collagen to simulate physiological conditions, dissimilarities were observed in the amplitude and behavior of the stress generated potentials between wet and dry samples. The induced electric potential was found to be dependent on the strain rate and more importantly, the relaxation time of the induced potential was much higher in wet samples. To justify the inconsistency, different hypotheses were proposed such as the p-n junction characteristic of apatite-collagen[35], which suggests bone was piezoelectric in one direction and piezoresistive in another. However, a notion that drew more recognition proposed that while piezoelectricity was accountable for stress induced potentials in dry bone, the mechanism responsible for wet bone was streaming potential[36, 37]. Streaming potential theory suggested that the stress-generated potential in wet bone was due to the flow of ion containing interstitial fluid through bone as a result of pressure. Streaming potential theory dominated after Pollack et al.[38] reported that the conductivity of the saturating fluid was significantly influential on the amplitude and polarity of the generated potentials and the longer relaxation time was due to the viscosity of the fluid. A newer theory of mechanosensation in bone suggests that the applied stress on bone is translated into biochemical signals by flowing interstitial fluid in the canaliculi-lacunae space and supplying bone cells with nutrients as well as conveying shear stress to cells[39]. In spite of the new theories, the debate exists whether one can entirely exclude piezoelectricity from mechanosensation. As illustrated in Figure 3, Ahn and Grodzinsky[40] suggest that piezoelectricity increases the surface charge density of collagen fibers and consequently increases the zeta potential, which intensifies the streaming potential as the following equation[38]:

$$
V=\frac{\zeta P \kappa}{4 \pi \sigma \eta}
$$


where $\zeta, P, \kappa, \sigma$ and $\eta$ are the zeta potential, the pressure on the bone, the dielectric permittivity, conductivity and viscosity of the interstitial fluid, respectively. Remarkably, they support their hypothesis by recalling the piezoelectric coefficients previously reported by Anderson et al. that show while the largest piezoelectric coefficients in dry bone are in the lateral axes, immersing the same bone in saline solution results in the largest piezoelectric coefficients in the longitudinal axis. This suggests that when placed in a saline solution, the electricity produced on the lateral surfaces due to piezoelectricity can be translated to zeta potential and consequently contribute to higher streaming potential along the longitudinal axis of bone[40].

\section{Cellular Response to Electric Stimulation}

In addition to piezoelectricity and streaming potentials in bone and other fibrous tissues, endogenous electric fields up to $500 \mathrm{mV} / \mathrm{mm}$ have been reported in living tissues[41]. The transport of ionic species and macromolecules associated with endogenous electric fields play crucial roles in embryonic development[42], wound healing[43] and neuronal regeneration[44]. There exists a difference in intracellular and extracellular ionic concentrations, resulting in a transmembrane potential of -10 to $-90 \mathrm{mV}$ in different types of cells. Shifts in transmembrane potential is known to alter cellular proliferation and differentiation[45], and exciting the resting

transmembrane potential in neurons can trigger self-propagation of action potential along the axon[46].

This vital role of electricity in living systems have inspired numerous investigations to either mimic biological piezoelectricity and endogenous electric fields or manipulate transmembrane potentials by external electrical stimulation to enhance cellular growth and differentiation. The attention in neural regeneration has been drawn to repairing peripheral nerve 
injuries through improved neuronal differentiation and directional outgrowth of neurites. Direct electric fields as low as $70 \mathrm{mV} / \mathrm{mm}$ have shown to facilitate the outgrowth of the neurites of embryonic chick dorsal root ganglions (DRG) toward the cathode[47]. Applying a direct electric field of $250 \mathrm{mV} / \mathrm{mm}$ or higher on Xenopus neurons resulted in more neurite-bearing cells with longer neurites directed towards the cathode and contracted neurites on the anode side (Figure 4)[48]. Promising results are not limited to neurons; an early study on the effect of electrical stimulation on bone formation showed that implanting insulated batteries in the medullary canal of canine femora caused substantial formation of endosteum near the cathode in a 14-21 day period[49]. Even in the absence of external electric stimulation, implanting poled sintered hydroxyapatite disks in canine cortical bone resulted in the filling of a $0.2 \mathrm{~mm}$ gap between the negatively charged hydroxyapatite surface and the cortical bone in 14 days, while no bone formation occurred using the unpoled hydroxyapatite before day 28[50].

Electrical stimulation can be applied through the substrate or the medium. While DC electrical stimulation through media aligns Schwann cells perpendicular to the direction of the electric field, AC electric field through the media changes the cellular morphology from bipolar spindles to flat and spread with more processes[51]. Applying currents through conductive polymers such as polypyrrole (PPy) and polyaniline (PANi) has been an alternative method for electrical stimulation. Even without electric current, cells have shown favorable extension and proliferation on substrates consisting of conductive polymers in comparison with control samples[52-54]. Figure 5 shows how applying a direct electric potential of $100 \mathrm{mV}$ across PPy film almost doubled the length of neurites of PC-12 cells in comparison with the non-stimulated films[55]. Applying a direct current of $10 \mu \mathrm{A}$ through PPy films also triggered significantly higher adsorption of fibronectin (FN) onto the surface, specifically in highly concentrated FN 
solutions and at early stages of exposure. The PC-12 cells seeded on these films grew up to 50\% longer neurites than on unstimulated films[56]. As an approach towards incorporating threedimensional (3D) features of fibrous scaffolds and electrical stimulation, Schmidt et al.[57] applied a direct electric field of $100 \mathrm{mV} / \mathrm{mm}$ through an electrospun 3D scaffold coated with PPy, and observed significant improvement in the number of neurite-bearing PC12 cells and their neurite lengths.

Another method to construct 3D conductive scaffolds is electrospinning blends of nonconductive and conductive polymers. Direct electrical stimulation of electrospun composites of 30 wt.\% PANi and poly(L-lactide-co- $\varepsilon$-caprolactone) copolymer with $20 \mathrm{~mA}$ increased the proliferation of NIH-3T3 fibroblasts[54]. Neural stem cells seeded on nanofibrous scaffolds composed of poly(e-caprolactone) (PCL), gelatin and $15 \mathrm{wt} . \%$ PANi also showed significantly higher proliferation as well as growing longer neurites in response to one hour of direct electrical stimulation of $100 \mathrm{mV} / \mathrm{mm}[58]$. Electrospun scaffolds composed of PANi and poly-L-lactic acid also increased the neurite lengths of C17.2 rat stem neural stem cells when stimulated with $100 \mathrm{mV} / \mathrm{mm}[53]$. In most direct electrical stimulation studies, there is an optimum electric field in the range of endogenous electric fields or transmembrane potential, over which there is either no significant improvement [57] or the field is detrimental to the cells[52, 54].

Alternating electric fields also have been investigated. Alternating electric fields have shown to cause morphological changes and significantly increased number of processes in Schwann cells, but did not lead to directional outgrowth[51]. Since endogenous electric fields and transmembrane potentials are direct rather than alternating, many neuronal studies use direct electrical stimulation. On the contrary, the periodic nature of the stress applied to bone has inspired researchers in bone repair to focus on alternating electric fields to enhance osteoblast 
proliferation and activity. Moreover, in order to avoid electrode implantation and consequently electrolytic byproducts, noninvasive stimulation for bone fracture healing drew widespread attention. Noninvasive bone growth stimulators are approved by the U.S. Food and Drug Administration (FDA) [59, 60], and are currently marketed for healing fractures and nonunions. In research, techniques implemented for osteogenic electrical stimulation varies from capacitively coupled stimulation[61-63], to applying electromagnetic waves using Helmholtz[6466] and solenoid coil[67, 68]. Capacitively coupled electrical stimulation have shown to significantly increase the proliferation[61] and matrix mineralization of osteoblast-like cells[63].

The mechanisms through which electrical stimulation causes cellular migration and alters proliferation and differentiation are not yet fully understood. It is speculated that the electric field effect is either direct by intracellular components such as ions, growth factors and receptors, or indirect by agglomeration or conformational change of extracellular ions and proteins[48, 55]. Free calcium cations $\left(\mathrm{Ca}^{2+}\right)$ are considered a major factor in both direct and indirect mechanisms of electrical stimulation. Electric fields redistribute $\mathrm{Ca}^{2+}$ in the extracellular matrix or on the substrate[51]. Intracellular $\mathrm{Ca}^{2+}$ concentrations are also reported to increase due to electrical stimulation[69]. Figure 6 illustrates an adaptation of the galvanotaxis of cells as reviewed by Mycielska et al.[41]. Direct electric field depolarizes the cathodal side of the cell and hyperpolarizes the anodal side. This leads to the diffusion of extracellular $\mathrm{Ca}^{2+}$ through the anodal side into the cell. Increase in the $\mathrm{Ca}^{2+}$ may cause actin depolymerization and consequently contraction on the anodal side, which pushes the cell forward and thus makes the cathodal side of the cell protrude[41]. This could explain the phenomenon observed by Patel and Poo[48] as shown in Figure 4, i.e. the outgrowth of the neurites on the cathodal side of the cell and the diminishing of the neurites on the anodal side. Patel and Poo, on the other hand, found 
that neither blocking $\mathrm{Na}^{+}$channels nor nullifying intercellular $\mathrm{Ca}^{2+}$ gradient stopped directional neurite outgrowth in cells exposed to direct electric field[48]. However, there was a larger distribution of concanavalin A receptors on the cathode side of the cell than on the anode side, which made them conclude that the effect of electrical stimulation on directional growth of neurons could be direct by preferential migration of membrane receptors[48]. Schmidt et al. reported that electrical stimulation could result in more favorable conformational changes in fibronectin, which facilitated the adsorption of more proteins onto the biomaterial[56]. Since some extracellular matrix proteins play critical roles in cellular attachment, more adhered proteins on the surface could improve cellular adhesion and outgrowth.

The effect of electrical stimulation on enhanced bone formation was initially based on the indirect hypothesis; piezoelectricity of bone generated electric fields that aggregated charged ions and macromolecules in the bone interstitial fluid, which resulted in enhanced osteoblast activity[32]. Direct electric fields are assumed to mobilize $\mathrm{Ca}^{2+}$ and $\mathrm{Mg}^{2+}$ towards the cathode or negatively charged surface and cause apatite formation, which can become a scaffold for bone formation by osteoblasts[50, 70]. Increased levels of gene expression for bone morphogenic proteins (BMP-2 and -4) as a result of electromagnetic stimulation were noted[66]. Zhuang et al.[61] also found that capacitively coupled electrical stimulation increased TGF- $\beta 1$ gene expression as well as the proliferation of osteoblasts. TGF- $\beta 1$ expression was modulated by the calcium-calmodulin pathway.

\section{Piezoelectric Materials in Tissue Regeneration Applications}

\section{Piezoceramics}


Using piezoelectric materials as tissue engineering scaffolds enables electrical stimulation without the need for electrodes, external source of electricity or implanting batteries, which also eliminates the chance of accumulating products of electrolysis. Piezoelectric scaffolds can generate electric pulses as a result of transient deformations, which can be imposed by attachment and migration of cells or body movements. The materials used in scaffolds needs to be biocompatible and possess reasonable piezoelectric coefficients. The most commonly used piezoelectric material in electronics is lead zirconate titanate (PZT)[71] owing to its notable piezoelectric and electromechanical coupling coefficients. PZT has been used to build a wirelessly powered nerve-cuff, in which the implanted piezoceramic was deformed by ultrasound radiated through the skin, and consequently generated electric pulses that could cause muscle-twitch in a rat's hind limb[72]. In another study, rat cortical neurons cultured on PZT slides coated with poly-L-lysine grew significantly longer axons, despite a decrease in cell number. Also the frequency and amplitude of the excitatory postsynaptic currents increased, suggesting that piezoelectricity could have augmented neuronal activity[73]. Nevertheless, 60 wt.\% of PZT is lead, which even in low doses causes serious health problems such as neurotoxicity [74], pregnancy complications [75], attention deficit hyperactivity[76] and slow growth rate in children[77]. There have been efforts to replace PZT with lead-free piezoceramics. Among popular lead-free piezoceramics, zinc oxide $(\mathrm{ZnO})$, barium titanate $(\mathrm{BT})$, potassium sodium niobate (KNN), lithium sodium potassium niobate (LNKN), and boron nitride nanotubes (BNNT) have substantial piezoelectric coefficients. One major concern about using piezoceramics in tissue engineering is the cytotoxicity of these materials. Most piezoelectric ceramics, such as PZT[78], ZnO[79], BT[80], KNN and LNKN[81], exhibit ion dissolution in biological fluids. While some of the released ions for instance $\mathrm{Pb}^{2+}$ could be toxic, others could 
be relatively safe or even favorable at low doses[82] and cytotoxic at higher concentrations[83]. Therefore, in some studies involving piezoceramics, the piezoelectric particles are embedded in polymer $[82,84,85]$ or ceramic [86-88] matrix composites to control ion dissolution. Although BNNTs are highly stable in aqueous solutions, their cytotoxicity is still of controversy [89-92]. Composites of $\mathrm{ZnO}$ nanoparticles in polyurethane have been employed to engineer neural tissues, which resulted in lower density of astrocytes as $\mathrm{ZnO}$ increased, particularly on composites with more than $10 \% \mathrm{ZnO}$. This was attributed to the increase in surface energy of the composites as a result of the increase in $\mathrm{ZnO}$, which could alter both adsorption and conformation of extracellular matrix proteins on the surface. Findings were particularly noteworthy because the accumulation of astrocytes on an implant results in glial scars, which can hinder neural regeneration[84]. Electrospun fibrous composite scaffolds made of $\mathrm{ZnO}$ particles and polyurethane (PU) resulted in improved attachment and proliferation of mouse fibroblasts on the composite scaffolds in comparison to pure PU scaffolds[85].

Barium titanate (BT) was the first lead-free piezoceramic that was investigated in bone repair. Initial results were promising: BT cylinders implanted in canine femora formed a strong interfacial bond with bone. However, no significant difference was observed between poled/piezoelectric BT implants and the unpoled ones[93]. Further in vivo studies using this piezoceramic were composites of hydroxyapatite (HA) and BT where results showed new bone formation on the BT/HA implant after just one week, while bone did not grow on HA implant until two weeks. Interestingly, bone formation was dependent on the direction of implantation (vertical or horizontal), which could indicate the possible role of piezoelectric coefficients in different directions[87]. The proliferation and attachment of human osteosarcoma cells on both poled and unpoled HA-90\%BT composite versus pure HA disks revealed no significant 
difference in vitro, possibly because the experiments took place in static conditions[86]. Similarly in a more recent study, fibroblasts on freeze-cast BT/HA composites showed no cytotoxicity, and the highest cell number was observed on HA-70\%BT, compared with HA90\%BT and HA-50\%BT[88]. Adding BT nanoparticles to electrospun PCL scaffolds also increased osteocalcin gene expression of pre-osteoblasts[82]. Attachment and internalization of glycol-chitosan coated BT nanoparticles to the cell membrane and even in the cytoplasm of mesenchymal stem cells significantly altered the conformation of the cytoskeleton and increased the stiffness of the cells, which resulted in enhanced osteogenic differentiation[94].

Potassium sodium niobate $(\mathrm{KNN})$ and lithium sodium potassium niobate $(\mathrm{LNKN})$ are two other lead-free piezoceramics with piezoelectric coefficients of almost two orders of magnitude larger than natural bone, whose cytotoxicities have been evaluated. The viability of mouse fibroblasts cultured on KNN and LNKN powders for 24 hours were respectively 84 and $58 \%$, although the value for LNKN could be improved to $72 \%$ by adjusting the $\mathrm{pH}$. The slightly higher toxicity of $\mathrm{LNKN}$ could be due to the release of $\mathrm{Li}^{+}$in the media after immersion of the piezoceramic[81]. In another study, rat osteoblasts showed better attachment and proliferation on the negatively charged surface of the poled LNKN porous scaffolds than unpoled scaffolds[95].

In a novel approach, Ciafoni et al.[96] internalized boron nitride nanotubes (BNNT) inside the cytoplasmic vesicles of PC12 cells and wirelessly agitated the piezoelectric nanotubes by external ultrasound. Their results showed that neurite lengths as well as the number of neurites per differentiated cell were significantly greater in cultures with BNNTs followed by ultrasound agitation. Interestingly, they also observed that blocking calcium channels diminished the response to stimulation, suggesting that electrical stimulation contributes to differentiation through calcium signaling pathways. 


\section{Piezopolymers}

Discovery of the piezoelectricity of polyvinylidene fluoride (PVDF) by Kawai[97] made this polymer a candidate substitute for PZT. Due to its flexibility and nontoxicity[98], PVDF has been used for a variety of biomedical applications, from tissue engineering scaffolds to implantable self-powered devices[99]. PVDF crystalizes in various phases. $\alpha$-PVDF has a transgauche conformation without a net dipole moment and is non-piezoelectric (Figure 7(a)). $\beta$ PVDF, however, has all-trans conformation, which exhibits a net dipole moment and is thus piezoelectric[100] (Figure 7(b)). Alternatively, poly[(vinylidenefluoride-co-trifluoroethylene] (PVDF-TrFE) is a copolymer with all-trans conformation, piezoelectricity and high electromechanical coupling coefficient[101] (Figure 7(c)).

Valentini et al.[102] used PVDF to build guidance channels for neuronal regeneration. They employed mechanical stretching to orient the dipoles and transform $\alpha-\mathrm{PVDF}$ to $\beta$-PVDF, followed by electric poling in order to fix the dipoles and achieve piezoelectric tubes to be used as sciatic nerve guidance channels. Rat sciatic nerves with $4 \mathrm{~mm}$ gaps were treated with nerve guidance channels. After 4 weeks of implantation, the numbers of myelinated axons in the midpoint of the piezoelectric tubes were significantly higher than the control tubes. In a following investigation, Valentini et al.[103] repeated the experiment with piezoelectric PVDFTrFE to avoid stretching. They poled two groups to have negatively charged and positively charged nerve guidance channels as well as an unpoled group. The positively poled tube led to the most myelinated axons in the regenerated nerves bridging the $10 \mathrm{~mm}$ gaps after 4 weeks, while negatively poled and unpoled tubes resulted in the intermediate and the fewest number of myelinated axons, respectively. Valentini et al.[104] also studied the differentiation of mouse 
neuroblastoma cells on poled and unpoled PVDF substrate after 24 to 96 hours and found that despite similar chemical and topographical properties of the piezoelectric and nonpiezoelectric substrates, the former resulted in significantly enhanced neurite outgrowth and extension.

In a series of studies, Arinzeh et al.[105-108] used electrospinning to construct fibrous piezoelectric scaffolds for neural and bone tissue engineering. Electrospun PVDF-TrFE fibrous scaffolds showed higher crystallinity and $\beta$-phase content as compared to the starting powder material. In a study establishing cytocompability, metabolic activity and gene expression of the cultured human dermal fibroblasts suggested adequate cellular proliferation and attachment on the PVDF-TrFE fibrous scaffolds during a 7 day period. Results were not significantly different from tissue culture plates as the control group. However, since plasma treated polystyrene used in tissue culture plates are favorable sites for the attachment and growth of anchorage-dependent cells such as fibroblasts, the comparability between the two groups suggested the cytocompatibility of the piezoelectric fibers[105]. In a subsequent study, electrospun PVDF and PVDF-TrFE fibrous scaffolds were used to examine neurite outgrowth using dorsal root ganglions (DRGs). Results showed that while neurites attached and extended on PVDF and PVDF-TrFE fibrous scaffolds, their attachment and extension on films casted from the same materials were poor, which suggested the 3-D fibrous environment facilitated neurite outgrowth. Measurement of average neurite lengths and the aspect ratio of the DRGs after 4 days of cell culture showed there was a linear relationship between fiber diameter and fiber alignment with neurite extension and directionality of the DRGs. Annealing the electrospun mats at $135^{\circ} \mathrm{C}$ for 96 hours increased the crystallinity and piezoelectric crystal phase content in the PVDF-TrFE scaffolds. Longest DRG neurite lengths were observed on annealed aligned PVDF-TrFE microfibrous scaffolds. In addition, fiber alignment had a dominant impact on neurite extension. 
Regardless of fiber diameter, alignment resulted in a significantly lower aspect ratios of the DRGs on both PVDF and PVDF-TrFE fibrous scaffolds indicating more directional extension, while random fibrous scaffolds resulted in radial neurite extension similar to the control group i.e. collagen-coated tissue culture plates[106].

Arinzeh et al.[107] investigated the differentiation of human neural stem/precursor cells (hNSC/NPC) on PVDF-TrFE fibrous scaffolds and films. Results showed that cells on electrospun piezoelectric fibrous scaffolds were mostly neuron-like $\beta$-III tubulins, while on nonpiezoelectric laminin-coated plates, mainly nestin was expressed. Fiber morphology and contact guidance, crystallinity and consequently the piezoelectricity of the PVDF-TrFE scaffolds may have accelerated the differentiation of hNSC/NPCs to neuron-like $\beta$-III tubulins. Although the cultures were performed in static conditions, the authors suggest that results may be attributed to transient surface charges generated due to minute deformation of the piezoelectric fibers by cellular attachment and migration. Figure 8 illustrates how alignment and annealing of the microfibers resulted in longer neurite extension and enhanced differentiation of hNSC/NPCs to neuron-like cells expressing $\beta$-III tubulin, respectively. While in unannealed samples nestin stained cells are still noticeable, in annealed samples cells expressing nestin diminish and cells expressimg $\beta$-III tubulin becomes dominant.

Using electrospun PVDF fibrous scaffolds to differentiate mesenchymal stem cells into osteoblasts indicated that fibers electrospun at higher voltages were more favorable than lower potentials[108]. Even though tissue culture plates had the highest attachment and proliferation of mesenchymal stem cells; at early days of culture, alkaline phosphatase activity and matrix mineralization on the electrospun scaffolds were superior, particularly on scaffolds electrospun at 
higher electric potentials. This could be attributed to the presence of more piezoelectric $\beta$-PVDF that could have enhanced osteogenic differentiation.

Guo et al.[109] electrospun blends of polyurethane (PU) and PVDF to study the effect of piezoelectricity on wound healing and fibroblast activity. For mechanical deformation, they used culture plates with flexible bottoms that could be biaxially stretched. Having observed an increase in the piezoelectric coefficient as well as a decrease in the mechanical properties of the composite scaffolds as a result of increasing PVDF/PU ratio, they used PVDF/PU of 1 as the optimum composition for culturing mouse embryo fibroblasts. In accordance with Arinzeh et al.'s results[105, 106, 108], comparison of the FTIR spectra, DSC thermograms and XRD patterns of PVDF powder and electrospun PVDF/PU scaffolds showed $\alpha$ to $\beta$ phase transformation as a result of electrospinning. As shown in figure 9, comparison of the wound healing rates of the fibroblasts cultured on the three groups shows that deformation of the electrospun PVDF/PU scaffolds by $8 \%$ at $0.5 \mathrm{~Hz}$ almost doubled the cellular migration to the scratched area after 24 hours, as opposed to undeformed PVDF/PU and deformed PU scaffolds as controls. Also, the number of cells attached onto the PVDF/PU was higher than the control samples. Their results demonstrated that the enhanced migration and adhesion was due to the piezoelectric response i.e. a combination of piezoelectric scaffold and deformation and not deformation or microstructure solely. Guo et al.[109] also implanted the PVDF/PU and PU scaffolds in three rat body parts: vertex with less deformation and higher blood flow; back and abdomen with higher deformation. Histological imaging showed that in the PU group, the vertex scaffold had enhanced fibrosis compared with back or abdomen scaffolds, whereas in PVDF/PU group, the three scaffolds had similar fibrosis levels. This finding was attributed to the high deformation rate in the back and abdomen that triggered piezoelectric response from the 
PVDF/PU scaffold. Moreover, the levels of fibrosis in PVDF/PU scaffolds were higher than PU scaffolds in all body parts. The authors attributed these changes in the alteration of the intracellular ion channels caused by the change in the permeability of cell membranes[109].

Royo-Gascon et al.[110] extruded, stretched and poled PVDF films to build substrates for rat spinal cord neurons. To avoid the indirect effect of protein adsorption at early stages as discussed before[56], they started mechanical deformation via vibration 24 hours after cell attachment. By vibrating the plates for 96 hours at $50 \mathrm{~Hz}$, the arborization, number of neurites, and cell density remarkably increased, while the opposite results were observed for the unpoled samples. They concluded that local calcium ion concentration as well as other second messenger molecules such as cAMP could be responsible for enhanced results caused by electric stimulation[110].

Similar to the previously discussed fibronectin (FN) adsorption to conductive polymers with direct electric currents[56], one possible approach to explicate favorable cellular response to piezoelectric materials is enhanced protein adsorption due to static or dynamic electric charges on the surface[111, 112]. Poling has shown to result in higher FN adsorption followed by increased cell numbers on $\beta$-PVDF films, possibly due to orientation of dipoles on the surface, which also manifests itself in higher hydrophilicity of poled $\beta$-PVDF samples compared to unpoled ones[111]. Both negatively and positively poled $\beta$-PVDF groups have been reported to result in enhanced osteogenic differentiation of adipose stem cells compared to the unpoled films. Negatively poled $\beta$-PVDF films lead to round and spread cells with significantly higher focal adhesion density. This has been attributed to changes in the conformation of adsorbed FN, exposing more favorable motifs for integrin receptors to attach[113]. 
Unlike PVDF, Poly-L-lactic acid (PLLA) is a biodegradable[114] polymer with helical structure and accordingly permanently oriented dipoles[115, 116]. The discovery of the piezoelectricity of PLLA by Fukada[117], inspired attempts to use this biocompatible and biodegradable polymer as a bone substitute with the capability to mimic the piezoelectricity of natural bone. Fukada et al.[118] implanted drawn and consequently piezoelectric PLLA rods in the intramedullary cavity of feline tibiae, and observed meaningfully higher callus formation in contrast to undrawn PLLA and polyethylene rods in a 4 to 8 week period. Interestingly, callus formation significantly increased as a result of increase in the draw ratio, and consequently higher piezoelectricity, which was an indication that the enhancement was due to the electricity generated through bending strain of the piezoelectric rod as a result of animal movement. Currently, PLLA is approved by the U.S. Food and Drug Administration (FDA) as a bone implant device[119, 120].

Most of the research on PLLA in tissue engineering has yet focused on the versatility of producing biodegradable and biocompatible nanofibrous scaffolds, without mentioning the piezoelectric aspect. Ramakrishna et al.[121, 122] have constructed fibrous PLLA scaffolds using phase separation and electrospinning to differentiate and grow neural stem-like cells. PLLA has been used as a material to incorporate other bioactive materials such as HA and collagen through electrospinning to grow human fetal osteoblasts[123] or endothelial cells derived from human mesenchymal stem cells[124]. In a more piezoelectricity-inspired approach, Barroca et al.[125] used a spin-coating technique to coat PLLA on $\mathrm{Pt} / \mathrm{TiO}_{2} / \mathrm{SiO}_{2} / \mathrm{Si}$ substrates and achieved a $300 \mathrm{~nm}$ thin film, which was subsequently recrystallized through heat treatment. Using PFM and a direct electric bias, the PLLA surface was locally poled. Fibronectin adsorption was studied on negatively poled, positively poled and unpoled PLLA thin films. 
Imaging the surface using AFM in water showed that independent of sign, significantly higher amounts of fibronectin were adsorbed on both positive and negative poled areas. The adsorbed fibronectin on poled surfaces were topographically similar to the fibronectin adsorbed on hydrophobic surfaces. Barroca et al. concluded that surface charges can alter the conformation or orientation of the adsorbed proteins, which may expose or hinder their cell-binding domains. Table 1 summarizes the abovementioned materials, their piezoelectric coefficients, and reported applications.

\section{Conclusion}

Electricity exists in living tissues in the form of stress-generated potentials, endogenous electric fields and transmembrane potentials. Numerous studies have been carried out on whether or not imitating these biological electric fields can enhance growth and repair. Some of these efforts have resulted in clinical trials or approved medical treatments. Implantation of piezoelectric materials in vivo has prompted encouraging results in repairing nerve injuries, bone formation and wound healing, which can be attributed to charge generation as a consequence of body movement and physiological stress on the piezoelectric material. Deformation of the piezoelectric scaffolds in vitro using mechanical or ultrasound agitation has also led to neurite extension, enhanced adhesion, differentiation and faster cellular migration. Even in the absence of deformation, piezoelectric scaffolds have exhibited favorable protein adsorption, cellular attachment and proliferation, possibly due to permanent polarization and surface charges of piezoelectric materials or transient deformation caused by the contraction and protrusion of the attached cells. Piezoelectric materials hold promise as the next generation of tissue engineering scaffolds. 


\section{Acknowledgements}

The authors would like to thank support from DOD W81XWH-14-1-0482 and NSF DMR1006510. 


\section{References}

[1] Curie P, Curie J. Développement, par pression, de l'électricité polaire dans les cristaux hémièdres à faces inclinées. Comptes rendus de l'Académie des sciences 1880;91:294-5.

[2] Martin AJP. Tribo-electricity in wool and hair. Proceedings of the Physical Society 1941;53:186.

[3] C Marshall R, Gillespie J. The Keratin Proteins of Wool, Horn and Hoof from Sheep. Australian Journal of Biological Sciences 1977;30:389-400.

[4] Wu DD, Irwin DM, Zhang YP. Molecular evolution of the keratin associated protein gene family in mammals, role in the evolution of mammalian hair. BMC Evol Biol 2008;8:1471-2148.

[5] Menefee E. Thermocurrent from Alpha-Helix Disordering in Keratin. In: Perlman MM, editor. Electrets, Charge Storage, and Transport in Dielectrics: Dielectrics and Insulation Division, Electrochemical Society; 1973. p. 661.

[6] Feughelman M, Lyman D, Menefee E, Willis B. The orientation of the $\alpha$-helices in $\alpha$-keratin fibres. International Journal of Biological Macromolecules 2003;33:149-52.

[7] Farrar D, Ren K, Cheng D, Kim S, Moon W, Wilson WL, et al. Permanent Polarity and Piezoelectricity of Electrospun $\alpha$-Helical Poly( $\alpha$-Amino Acid) Fibers. Advanced Materials 2011;23:3954-8.

[8] Alparone A. Response electric properties of $\alpha$-helix polyglycines: A CAM-B3LYP DFT investigation. Chemical Physics Letters 2013;563:88-92.

[9] Yasuda I. On the piezoelectric activity of bone. J Japanese Orthop Surg Soc 1954;28:267-71.

[10] Fukada E, Yasuda I. On the Piezoelectric Effect of Bone. Journal of the Physical Society of Japan 1957;12:1158-62.

[11] Hassenkam T, Fantner GE, Cutroni JA, Weaver JC, Morse DE, Hansma PK. Highresolution AFM imaging of intact and fractured trabecular bone. Bone 2004;35:4-10.

[12] Ramachandran GN, Kartha G. Structure of Collagen. Nature 1955;176:593-5.

[13] Momeni K, Asthana A, Prasad A, Yap Y, Shahbazian-Yassar R. Structural inhomogeneity and piezoelectric enhancement in ZnO nanobelts. Appl Phys A 2012;109:95-100.

[14] Minary-Jolandan M, Yu M-F. Mechanical and Electromechanical Characterization of OneDimensional Piezoelectric Nanomaterials. In: Ciofani G, Menciassi A, editors. Piezoelectric Nanomaterials for Biomedical Applications: Springer Berlin Heidelberg; 2012. p. 63-91.

[15] Minary-Jolandan M, Yu MF. Nanoscale characterization of isolated individual type I collagen fibrils: polarization and piezoelectricity. Nanotechnology 2009;20:0957-4484.

[16] Minary-Jolandan M, Yu M-F. Uncovering Nanoscale Electromechanical Heterogeneity in the Subfibrillar Structure of Collagen Fibrils Responsible for the Piezoelectricity of Bone. ACS Nano 2009;3:1859-63.

[17] Kay MI, Young RA, Posner AS. Crystal Structure of Hydroxyapatite. Nature 1964;204:1050-2.

[18] Gruverman A, Wu D, Rodriguez BJ, Kalinin SV, Habelitz S. High-resolution imaging of proteins in human teeth by scanning probe microscopy. Biochemical and Biophysical Research Communications 2007;352:142-6.

[19] Calderín L, Stott MJ, Rubio A. Electronic and crystallographic structure of apatites. Physical Review B 2003;67:134106. 
[20] Lang SB, Tofail SAM, Kholkin AL, Wojtaś M, Gregor M, Gandhi AA, et al. Ferroelectric Polarization in Nanocrystalline Hydroxyapatite Thin Films on Silicon. Sci Rep 2013;3.

[21] Lang SB. Pyroelectric Effect in Bone and Tendon. Nature 1966;212:704-5.

[22] Marino AA, Becker RO. Piezoelectricity in hydrated frozen bone and tendon. Nature 1975;253:627-8.

[23] Williams WS, Breger L. Piezoelectricity in tendon and bone. Journal of Biomechanics 1975;8:407-13.

[24] Liboff AR, Shamos MH. Piezoelectric effect in dentin. J Dent Res 1971;50:516.

[25] Marino AA, Gross BD. Piezoelectricity in cementum, dentine and bone. Arch Oral Biol 1989;34:507-9.

[26] Shamos MH, Lavine LS. Piezoelectricity as a Fundamental Property of Biological Tissues. Nature 1967;213:267-9.

[27] Bassett CA, Pawluk RJ. Electrical behavior of cartilage during loading. Science (New York, NY) 1972;178:982-3.

[28] Shubnikov AV, Zheludev IS, Konstantinova VP, Silvestrova IM. Etude des Textures Piezoelectriques. 1958.

[29] Fukada E, Sasaki S. Piezoelectricity of $\alpha$-chitin. Journal of Polymer Science: Polymer Physics Edition 1975;13:1845-7.

[30] Duchesne J, Depireux J, Bertinchamps A, Cornet N, Van Der Kaa JM. Thermal and Electrical Properties of Nucleic Acids and Proteins. Nature 1960;188:405-6.

[31] Wolff J. Das gesetz der transformation der knochen. DMW-Deutsche Medizinische Wochenschrift 1892;19:1222-4.

[32] Bassett CAL. Biologic significance of piezoelectricity. Calcified Tissue International $1967 ; 1: 252-72$.

[33] Cochran GVB. Electromechanical characteristics of moist bone 1966.

[34] Anderson JC, Eriksson C. Electrical Properties of Wet Collagen. Nature 1968;218:166-8.

[35] Becker RO, Brown FM. Photoelectric effects in human bone. Nature 1965;206:1325-8.

[36] Johnson MW, Chakkalakal DA, Harper RA, Katz JL. Comparison of the electromechanical effects in wet and dry bone. Journal of Biomechanics 1980;13:437-42.

[37] Gross D, Williams WS. Streaming potential and the electromechanical response of physiologically-moist bone. Journal of Biomechanics 1982;15:277-95.

[38] Pienkowski D, Pollack SR. The origin of stress-generated potentials in fluid-saturated bone. J Orthop Res 1983;1:30-41.

[39] Riddle RC, Donahue HJ. From streaming-potentials to shear stress: 25 years of bone cell mechanotransduction. J Orthop Res 2009;27:143-9.

[40] Ahn AC, Grodzinsky AJ. Relevance of collagen piezoelectricity to "Wolff's Law": A critical review. Medical Engineering \& Physics 2009;31:733-41.

[41] Mycielska ME, Djamgoz MB. Cellular mechanisms of direct-current electric field effects: galvanotaxis and metastatic disease. J Cell Sci 2004;117:1631-9.

[42] Nuccitelli R. Endogenous electric fields in embryos during development, regeneration and wound healing. Radiat Prot Dosimetry 2003;106:375-83.

[43] Nuccitelli R. A Role for Endogenous Electric Fields in Wound Healing. Current Topics in Developmental Biology: Academic Press; 2003. p. 1-26.

[44] McCaig CD, Rajnicek AM, Song B, Zhao M. Has electrical growth cone guidance found its potential? Trends in Neurosciences 2002;25:354-9. 
[45] Sundelacruz S, Levin M, Kaplan DL. Role of membrane potential in the regulation of cell proliferation and differentiation. Stem Cell Rev 2009;5:231-46.

[46] McCormick DA. Chapter 12 - Membrane Potential and Action Potential. In: Byrne JH, Heidelberger R, Waxham MN, editors. From Molecules to Networks (Third Edition). Boston: Academic Press; 2014. p. 351-76.

[47] Jaffe LF, Poo M-M. Neurites grow faster towards the cathode than the anode in a steady field. Journal of Experimental Zoology 1979;209:115-27.

[48] Patel N, Poo MM. Orientation of neurite growth by extracellular electric fields. J Neurosci 1982;2:483-96.

[49] Bassett CAL, Pawluk RJ, Becker RO. Effects of Electric Currents on Bone In Vivo. Nature 1964;204:652-4.

[50] Kobayashi T, Nakamura S, Yamashita K. Enhanced osteobonding by negative surface charges of electrically polarized hydroxyapatite. Journal of Biomedical Materials Research 2001;57:477-84.

[51] Nguyen HT, Wei C, Chow JK, Nguy L, Nguyen HK, Schmidt CE. Electric field stimulation through a substrate influences Schwann cell and extracellular matrix structure. J Neural Eng 2013;10:1741-2560.

[52] Schmidt CE, Shastri V, Furnish EJ, Langer R. Electrical Stimulation Of Neurite Outgrowth And Nerve Regeneration. Biomedical Engineering Conference, 1998 Proceedings of the 17th Southern: IEEE; 1998. p. 117-.

[53] Prabhakaran MP, Ghasemi-Mobarakeh L, Jin G, Ramakrishna S. Electrospun conducting polymer nanofibers and electrical stimulation of nerve stem cells. J Biosci Bioeng 2011;112:5017.

[54] Jeong SI, Jun ID, Choi MJ, Nho YC, Lee YM, Shin H. Development of Electroactive and Elastic Nanofibers that contain Polyaniline and Poly(L-lactide-co- $\varepsilon$-caprolactone) for the Control of Cell Adhesion. Macromolecular Bioscience 2008;8:627-37.

[55] Schmidt CE, Shastri VR, Vacanti JP, Langer R. Stimulation of neurite outgrowth using an electrically conducting polymer. Proceedings of the National Academy of Sciences 1997;94:8948-53.

[56] Kotwal A, Schmidt CE. Electrical stimulation alters protein adsorption and nerve cell interactions with electrically conducting biomaterials. Biomaterials 2001;22:1055-64.

[57] Lee JY, Bashur CA, Goldstein AS, Schmidt CE. Polypyrrole-coated electrospun PLGA nanofibers for neural tissue applications. Biomaterials 2009;30:4325-35.

[58] Ghasemi-Mobarakeh L, Prabhakaran MP, Morshed M, Nasr-Esfahani MH, Ramakrishna S. Electrical stimulation of nerve cells using conductive nanofibrous scaffolds for nerve tissue engineering. Tissue Eng Part A 2009;15:3605-19.

[59] FDA. Premarket Approval. 1986.

[60] FDA. Premarket Approval. 1999.

[61] Zhuang H, Wang W, Seldes RM, Tahernia AD, Fan H, Brighton CT. Electrical Stimulation Induces the Level of TGF- $\beta 1$ mRNA in Osteoblastic Cells by a Mechanism Involving Calcium/Calmodulin Pathway. Biochemical and Biophysical Research Communications 1997;237:225-9.

[62] Hartig M, Joos U, Wiesmann H-P. Capacitively coupled electric fields accelerate proliferation of osteoblast-like primary cells and increase bone extracellular matrix formation in vitro. Eur Biophys J 2000;29:499-506. 
[63] Wiesmann H-P, Hartig M, Stratmann U, Meyer U, Joos U. Electrical stimulation influences mineral formation of osteoblast-like cells in vitro. Biochimica et Biophysica Acta (BBA) Molecular Cell Research 2001;1538:28-37.

[64] Cane V, Botti P, Soana S. Pulsed magnetic fields improve osteoblast activity during the repair of an experimental osseous defect. J Orthop Res 1993;11:664-70.

[65] Lohmann CH, Schwartz Z, Liu Y, Guerkov H, Dean DD, Simon B, et al. Pulsed electromagnetic field stimulation of MG63 osteoblast-like cells affects differentiation and local factor production. J Orthop Res 2000;18:637-46.

[66] Bodamyali T, Bhatt B, Hughes FJ, Winrow VR, Kanczler JM, Simon B, et al. Pulsed electromagnetic fields simultaneously induce osteogenesis and upregulate transcription of bone morphogenetic proteins 2 and 4 in rat osteoblasts in vitro. Biochem Biophys Res Commun 1998;250:458-61.

[67] Takano-Yamamoto T, Kawakami M, Sakuda M. Effect of a Pulsing Electromagnetic Field on Demineralized Bone-matrix-induced Bone Formation in a Bony Defect in the Premaxilla of Rats. Journal of Dental Research 1992;71:1920-5.

[68] Chang WH-S, Chen L-T, Sun J-S, Lin F-H. Effect of pulse-burst electromagnetic field stimulation on osteoblast cell activities. Bioelectromagnetics 2004;25:457-65.

[69] Onuma EK, Hui SW. Electric field-directed cell shape changes, displacement, and cytoskeletal reorganization are calcium dependent. J Cell Biol 1988;106:2067-75.

[70] Yamashita K, Oikawa N, Umegaki T. Acceleration and Deceleration of Bone-Like Crystal Growth on Ceramic Hydroxyapatite by Electric Poling. Chemistry of Materials 1996;8:2697700.

[71] Shirane G, Suzuki K, Takeda A. Phase Transitions in Solid Solutions of PbZrO3 and PbTiO3 (II) X-ray Study. Journal of the Physical Society of Japan 1952;7:12-8.

[72] Larson PJ, Towe BC. Miniature ultrasonically powered wireless nerve cuff stimulator. Neural Engineering (NER), 2011 5th International IEEE/EMBS Conference on2011. p. 265-8. [73] Wen J, Liu M. Piezoelectric Ceramic (PZT) Modulates Axonal Guidance Growth of Rat Cortical Neurons via RhoA, Rac1, and Cdc42 Pathways. J Mol Neurosci 2014;52:323-30.

[74] Davis JM, Otto DA, Weil DE, Grant LD. The comparative developmental neurotoxicity of lead in humans and animals. Neurotoxicology and Teratology 1990;12:215-29.

[75] Vigeh M, Yokoyama K, Shinohara A, Afshinrokh M, Yunesian M. Early pregnancy blood lead levels and the risk of premature rupture of the membranes. Reproductive Toxicology 2010;30:477-80.

[76] Ha M, Kwon H-J, Lim M-H, Jee Y-K, Hong Y-C, Leem J-H, et al. Low blood levels of lead and mercury and symptoms of attention deficit hyperactivity in children: A report of the children's health and environment research (CHEER). NeuroToxicology 2009;30:31-6.

[77] Shukla R, Bornschein RL, Dietrich KN, Buncher CR, Berger OG, Hammond PB, et al. Fetal and Infant Lead Exposure: Effects on Growth in Stature. Pediatrics October 1, 1989;84:604 -12

[78] Chen WP, Chan HLW, Yiu FCH, Ng KMW, Liu PCK. Water-induced degradation in lead zirconate titanate piezoelectric ceramics. Applied Physics Letters 2002;80:3587-9.

[79] Zhou J, Xu NS, Wang ZL. Dissolving Behavior and Stability of ZnO Wires in Biofluids: A Study on Biodegradability and Biocompatibility of $\mathrm{ZnO}$ Nanostructures. Advanced Materials 2006;18:2432-5.

[80] Nesbitt HW, Bancroft GM, Fyfe WS, Karkhanis SN, Nishijima A, Shin S. Thermodynamic stability and kinetics of perovskite dissolution. Nature 1981;289:358-62. 
[81] Yu S-W, Kuo S-T, Tuan W-H, Tsai Y-Y, Wang S-F. Cytotoxicity and degradation behavior of potassium sodium niobate piezoelectric ceramics. Ceramics International 2012;38:2845-50.

[82] Bagchi A, Meka SRK, Rao BN, Chatterjee K. Perovskite ceramic nanoparticles in polymer composites for augmenting bone tissue regeneration. Nanotechnology 2014;25:485101.

[83] Lin W, Xu Y, Huang C-C, Ma Y, Shannon K, Chen D-R, et al. Toxicity of nano- and microsized ZnO particles in human lung epithelial cells. J Nanopart Res 2009;11:25-39.

[84] Seil JT, Webster TJ. Decreased astroglial cell adhesion and proliferation on zinc oxide nanoparticle polyurethane composites. Int J Nanomedicine 2008;3:523-31.

[85] Amna T, Hassan MS, Sheikh FA, Lee HK, Seo KS, Yoon D, et al. Zinc oxide-doped poly(urethane) spider web nanofibrous scaffold via one-step electrospinning: a novel matrix for tissue engineering. Appl Microbiol Biotechnol 2013;97:1725-34.

[86] Baxter F, Turner I, Bowen C, Gittings J, Chaudhuri J. An in vitro study of electrically active hydroxyapatite-barium titanate ceramics using Saos-2 cells. J Mater Sci: Mater Med 2009;20:1697-708.

[87] Jianqing F, Huipin Y, Xingdong Z. Promotion of osteogenesis by a piezoelectric biological ceramic. Biomaterials 1997;18:1531-4.

[88] Zhang Y, Chen L, Zeng J, Zhou K, Zhang D. Aligned porous barium titanate/hydroxyapatite composites with high piezoelectric coefficients for bone tissue engineering. Materials Science and Engineering: C 2014;39:143-9.

[89] Ciofani G, Danti S, D’Alessandro D, Moscato S, Menciassi A. Assessing cytotoxicity of boron nitride nanotubes: Interference with the MTT assay. Biochemical and Biophysical Research Communications 2010;394:405-11.

[90] Chen X, Wu P, Rousseas M, Okawa D, Gartner Z, Zettl A, et al. Boron Nitride Nanotubes Are Noncytotoxic and Can Be Functionalized for Interaction with Proteins and Cells. Journal of the American Chemical Society 2009;131:890-1.

[91] Horváth L, Magrez A, Golberg D, Zhi C, Bando Y, Smajda R, et al. In Vitro Investigation of the Cellular Toxicity of Boron Nitride Nanotubes. ACS Nano 2011;5:3800-10.

[92] Ciofani G, Del Turco S, Rocca A, de Vito G, Cappello V, Yamaguchi M, et al. Cytocompatibility evaluation of gum Arabic-coated ultra-pure boron nitride nanotubes on human cells. Nanomedicine (London, England) 2014;9:773-88.

[93] Park JB, Kelly BJ, Kenner GH, von Recum AF, Grether MF, Coffeen WW. Piezoelectric ceramic implants: in vivo results. J Biomed Mater Res 1981;15:103-10.

[94] Ciofani G, Ricotti L, Canale C, D’Alessandro D, Berrettini S, Mazzolai B, et al. Effects of barium titanate nanoparticles on proliferation and differentiation of rat mesenchymal stem cells. Colloids and Surfaces B: Biointerfaces 2013;102:312-20.

[95] Wang Q, Yang J, Zhang W, Khoie R, Li YM, Zhu JG, et al. Manufacture and cytotoxicity of a lead-free piezoelectric ceramic as a bone substitute-consolidation of porous lithium sodium potassium niobate by cold isostatic pressing. Int J Oral Sci 2009;1:99-104.

[96] Ciofani G, Danti S, D’Alessandro D, Ricotti L, Moscato S, Bertoni G, et al. Enhancement of Neurite Outgrowth in Neuronal-Like Cells following Boron Nitride Nanotube-Mediated Stimulation. ACS Nano 2010;4:6267-77.

[97] Kawai H. The Piezoelectricity of Poly (vinylidene Fluoride). Japanese Journal of Applied Physics 1969;8:975.

[98] Foster FS, Harasiewicz KA, Sherar MD. A history of medical and biological imaging with polyvinylidene fluoride (PVDF) transducers. Ultrasonics, Ferroelectrics, and Frequency Control, IEEE Transactions on 2000;47:1363-71. 
[99] Liu X, Wang X, Zhao H, Du Y. Myocardial Cell Pattern on Piezoelectric Nanofiber Mats for Energy Harvesting. Journal of Physics: Conference Series 2014;557:012057.

[100] Chelakara Satyanarayana K, Bolton K. Molecular dynamics simulations of $\alpha$ - to $\beta$ poly(vinylidene fluoride) phase change by stretching and poling. Polymer 2012;53:2927-34.

[101] Ohigashi H, Koga K, Suzuki M, Nakanishi T, Kimura K, Hashimoto N. Piezoelectric and ferroelectric properties of $\mathrm{P}$ (VDF-TrFE) copolymers and their application to ultrasonic transducers. Ferroelectrics 1984;60:263-76.

[102] Aebischer P, Valentini RF, Dario P, Domenici C, Guénard V, Winn SR, et al. Piezoelectric Nerve Guidance Channels Enhance Peripheral Nerve Regeneration. ASAIO Journal 1987;33:457-8.

[103] Fine EG, Valentini RF, Bellamkonda R, Aebischer P. Improved nerve regeneration through piezoelectric vinylidenefluoride-trifluoroethylene copolymer guidance channels. Biomaterials 1991;12:775-80.

[104] Valentini RF, Vargo TG, Gardella Jr JA, Aebischer P. Electrically charged polymeric substrates enhance nerve fibre outgrowth In vitro. Biomaterials 1992;13:183-90.

[105] Weber N, Lee YS, Shanmugasundaram S, Jaffe M, Arinzeh TL. Characterization and in vitro cytocompatibility of piezoelectric electrospun scaffolds. Acta Biomaterialia 2010;6:3550-6. [106] Lee Y-S, Collins G, Livingston Arinzeh T. Neurite extension of primary neurons on electrospun piezoelectric scaffolds. Acta Biomaterialia 2011;7:3877-86.

[107] Lee YS, Arinzeh TL. The influence of piezoelectric scaffolds on neural differentiation of human neural stem/progenitor cells. Tissue Eng Part A 2012;18:2063-72.

[108] Damaraju SM, Wu S, Jaffe M, Arinzeh TL. Structural changes in PVDF fibers due to electrospinning and its effect on biological function. Biomedical Materials 2013;8:045007.

[109] Guo HF, Li ZS, Dong SW, Chen WJ, Deng L, Wang YF, et al. Piezoelectric PU/PVDF electrospun scaffolds for wound healing applications. Colloids Surf B Biointerfaces 2012;96:2936.

[110] Royo-Gascon N, Wininger M, Scheinbeim JI, Firestein BL, Craelius W. Piezoelectric substrates promote neurite growth in rat spinal cord neurons. Ann Biomed Eng 2013;41:112-22.

[111] Ribeiro C, Panadero JA, Sencadas V, Lanceros-Méndez S, Tamaño MN, Moratal D, et al. Fibronectin adsorption and cell response on electroactive poly(vinylidene fluoride) films. Biomedical Materials 2012;7:035004.

[112] Ribeiro C, Pärssinen J, Sencadas V, Correia V, Miettinen S, Hytönen VP, et al. Dynamic piezoelectric stimulation enhances osteogenic differentiation of human adipose stem cells. Journal of Biomedical Materials Research Part A 2015;103:2172-5.

[113] Pärssinen J, Hammarén H, Rahikainen R, Sencadas V, Ribeiro C, Vanhatupa S, et al. Enhancement of adhesion and promotion of osteogenic differentiation of human adipose stem cells by poled electroactive poly(vinylidene fluoride). Journal of Biomedical Materials Research Part A 2015;103:919-28.

[114] Tamai H, Igaki K, Kyo E, Kosuga K, Kawashima A, Matsui S, et al. Initial and 6-month results of biodegradable poly-l-lactic acid coronary stents in humans. Circulation 2000;102:399404.

[115] Fukada E. Bioelectrets and biopiezoelectricity. Electrical Insulation, IEEE Transactions on 1992;27:813-9.

[116] Kobayashi J, Asahi T, Ichiki M, Oikawa A, Suzuki H, Watanabe T, et al. Structural and optical properties of poly lactic acids. Journal of Applied Physics 1995;77:2957-73. 
[117] Fukada E. Piezoelectric properties of poly-L-lactic acid. Reports on Progress in Polymer Physics in Japan 1991;34:269-72.

[118] Ikada Y, Shikinami Y, Hara Y, Tagawa M, Fukada E. Enhancement of bone formation by drawn poly(L-lactide). J Biomed Mater Res 1996;30:553-8.

[119] FDA. 510(k) Summary. 2001.

[120] FDA. 510(k) Summary. 2008.

[121] Yang F, Murugan R, Ramakrishna S, Wang X, Ma YX, Wang S. Fabrication of nanostructured porous PLLA scaffold intended for nerve tissue engineering. Biomaterials 2004;25:1891-900.

[122] Yang F, Murugan R, Wang S, Ramakrishna S. Electrospinning of nano/micro scale poly(L-lactic acid) aligned fibers and their potential in neural tissue engineering. Biomaterials 2005;26:2603-10.

[123] Prabhakaran MP, Venugopal J, Ramakrishna S. Electrospun nanostructured scaffolds for bone tissue engineering. Acta Biomaterialia 2009;5:2884-93.

[124] Jia L, Prabhakaran MP, Qin X, Ramakrishna S. Stem cell differentiation on electrospun nanofibrous substrates for vascular tissue engineering. Materials Science and Engineering: $\mathrm{C}$ 2013;33:4640-50.

[125] Barroca N, Vilarinho PM, Daniel-da-Silva AL, Wu A, Fernandes MH, Gruverman A. Protein adsorption on piezoelectric poly(L-lactic) acid thin films by scanning probe microscopy. Applied Physics Letters 2011;98:133705.

[126] Minary-Jolandan M, Yu M-F. Shear piezoelectricity in bone at the nanoscale. Applied Physics Letters 2010;97:153127.

[127] Shrout T, Zhang S. Lead-free piezoelectric ceramics: Alternatives for PZT? J Electroceram 2007;19:113-26.

[128] Christman JA, Woolcott RR, Kingon AI, Nemanich RJ. Piezoelectric measurements with atomic force microscopy. Applied Physics Letters 1998;73:3851-3.

[129] Berlincourt D, Jaffe H. Elastic and Piezoelectric Coefficients of Single-Crystal Barium Titanate. Physical Review 1958;111:143-8.

[130] Ying C, Jim SW. Synthesis of Boron Nitride Nanotubes Using a Ball-Milling and Annealing Method. Nanoengineering of Structural, Functional and Smart Materials: CRC Press; 2005.

[131] Tashiro K, Kobayashi M, Tadokoro H, Fukada E. Calculation of Elastic and Piezoelectric Constants of Polymer Crystals by a Point Charge Model: Application to Poly(vinylidene fluoride) Form I. Macromolecules 1980;13:691-8.

[132] Sharma P, Wu D, Poddar S, Reece TJ, Ducharme S, Gruverman A. Orientational imaging in polar polymers by piezoresponse force microscopy. Journal of Applied Physics 2011;110:052010.

[133] Lee YS, Collins G, Arinzeh TL. Neural differentiation of human neural stem/progenitor cells on piezoelectric scaffolds. Bioengineering Conference, Proceedings of the 2010 IEEE 36th Annual Northeast2010. p. 1-2.

[134] Ochiai T, Fukada E. Electromechanical Properties of Poly-L-Lactic Acid. Japanese Journal of Applied Physics 1998;37:3374. 
Graphical Abstract Figure Caption: Upon deformation, the generated surface charges induced by the piezoelectric material redistribute extracellular proteins and ions. Changes in streaming potential, aggregation of ionic species and adsorption of select proteins, such as fibronectin, on the material surface that can facilitate cell-material interaction can result. An influx of ions into the cells may also occur which can promote cell behavior/function on piezoelectric materials.

\section{Figure Legends}

Figure 1: Schematic illustration of permanent polarization in $\alpha$-helix. Red arrows demonstrate the direction of the dipole moment.

Figure 2: Topography of a single collagen fibril imaged by atomic force microscopy (a), and the amplitude of its corresponding shear piezoelectricity acquired by piezoforce microscopy in the lateral mode (b).[16]

Figure 3: Ahn and Grodzinsky's hypothesized model illustrating how applied stress on bone results in greater surface charges, which consequently increases zeta potential, streaming potential, electroosmosis and dynamic stiffness as well as decreases hydraulic permeability in the open-circuit condition.[40]

Figure 4: Direction and outgrowth of the neurites (labeled 1 and 2) of a bipolar neuron as a result of stimulation by a $500 \mathrm{mV} / \mathrm{mm}$ electric field. The black arrow shows the direction of the electric field. The neuron at the beginning of the electrical stimulation (A); after 2 hours of exposure to the electric field, neurite 1 has noticeably grown towards the cathode (B); 4 hours of stimulation in the same direction resulted in further extension of neurite 1 as well as its branching, while neurite 2 has almost diminished (C); 2 hours after changing the direction of the electric field, the tips of neurite 1 curved and neurite 2 grew towards the new cathode (D).[48] 
Figure 5: Differentiation of PC-12 cells on PPy films without (A) and with (B) the application of $100 \mathrm{mV}$ across the film. The scale bar is $100 \mu \mathrm{m} .[55]$

Figure 6: A cell with insignificant voltage-gated $\mathrm{Ca}^{2+}$ channels at resting transmembrane potential (a); application of a direct electric field redistributes the intracellular charges resulting in the depolarization and hyperpolarization of the cathodal and anodal sides of the cell, respectively. Extracellular $\mathrm{Ca}^{2+}$ is consequently diffused through the anodal side (b). The increase in the intracellular $\mathrm{Ca}^{2+}$ on the anodal side depolymerizes actin. The result is the contraction of the anodal side and protrusion of the cathodal side (c) (adapted from Mycielska $e t$ al. [41]).

Figure 7: Chemical structures of $\alpha$-PVDF with trans-gauche conformation and no net dipole moment (a); $\beta$-PVDF with all-trans conformation having a net dipole moment (b); and PVDFTrFE copolymer with an inherent net dipole moment (c).

Figure 8: Confocal fluorescent microscopic images of the cells cultured in induction media on electrospun microfibrous PVDF-TrFE unannealed random (a), unannealed aligned (b), annealed random (c) and annealed aligned (d) scaffolds after 9 days. Anti-nestin (green), anti- $\beta$-III tubulin (red), anti-GFAP (blue), and counterstained with DAPI (blue).[107]

Figure 9: Imaging of the migration of fibroblasts into the wound on undeformed PU/PVDF scaffolds, deformed PU scaffolds and deformed PVDF/PU scaffolds at different time points (A); and their average wound healing speeds from the corresponding scaffolds (B).[109] 
Table 1: Summary of piezoelectric materials, their piezoelectric coefficients and applications. ${ }^{*} \mathrm{ZnO}$ thin films; ${ }^{* *} \mathrm{BT}$ single crystals; ${ }^{* * *} \mathrm{PVDF}-\mathrm{TrFE}(80: 20) ;{ }^{* * * *}$ theoretically calculated.

\begin{tabular}{|c|c|c|}
\hline $\begin{array}{l}\text { Piezoelectric } \\
\text { Material }\end{array}$ & $\begin{array}{c}\text { Piezoelectric } \\
\text { Coefficient }(\mathrm{pC} / \mathrm{N})\end{array}$ & Applications \\
\hline Bone & $\mathrm{d}_{15}=0.1-0.3[126]$ & Shear piezoelectricity of cortical bone by PFM[126]. \\
\hline Collagen & $\mathrm{d}_{15}=\sim 2[16]$ & $\begin{array}{l}\text { Most abundant protein in human body[12], responsible for } \\
\text { the piezoelectricity of bone[10]. }\end{array}$ \\
\hline PZT & $d_{33}=225-590[127]$ & $\begin{array}{l}\text { Neural stimulator in vivo[72]. } \\
\text { Axonal growth in vitro[73]. }\end{array}$ \\
\hline $\mathrm{ZnO}$ & $\mathrm{d}_{33}{ }^{*}=12.4[128]$ & $\begin{array}{l}\mathrm{PU} / \mathrm{ZnO} \text { nanoparticles composite for nerve guidance } \\
\text { channels[84]. }\end{array}$ \\
\hline BNNT & $\mathrm{d}_{33}{ }^{* *}=191[129]$ & $\begin{array}{l}\text { Sintered BT in bone growth in vivo[93]. } \\
\text { BT/HA composite for bone growth in vivo[87]. } \\
\text { BT/HA composite to grow osteoblast-like cells in } \\
\text { vitro[86]. } \\
\text { PCL/BT nanoparticles composite for osteogenic } \\
\text { differentiation in vitro[82]. } \\
\text { BT nanoparticles for osteogenic differentiation in } \\
\text { vitro[94]. } \\
\text { Porous BT/HA composites for cytotoxicity tests[88]. }\end{array}$ \\
\hline LNKN & $\mathrm{d}_{33}=89[81]$ & Bone growth in vitro[95]. \\
\hline $\begin{array}{c}\text { BN } \\
\text { nanotubes }\end{array}$ & $\mathrm{d}_{33}=0.3[130]$ & Neural growth in vitro[96]. \\
\hline PVDF & $\mathrm{d}_{33}{ }^{* * * *}=-25[131]$ & $\begin{array}{l}\text { Nerve guidance channels in vivo[102]. } \\
\text { Neural growth in vitro [104]. } \\
\text { PVDF/PU composite for wound healing in vitro and in } \\
\text { vivo[109]. } \\
\text { Fibronectin adsorption and cellular attachment[111]. } \\
\text { Bone formation in vitro[108]. } \\
\text { Neural growth in vitro[110]. } \\
\text { Osteogenic differentiation in vitro[112, 113] }\end{array}$ \\
\hline PVDF-TrFE & $d_{33}^{* * *}=-25.2[132]$ & $\begin{array}{l}\text { Nerve guidance channels in vivo[103]. } \\
\text { Neural differentiation in vitro[133]. } \\
\text { Neural growth in vitro[106]. }\end{array}$ \\
\hline PLLA & $\mathrm{d}_{14}=-9.82[134]$ & $\begin{array}{l}\text { Bone growth in vivo[118]. } \\
\text { Neural differentiation and growth in vitro[121, 122]. } \\
\text { PLLA blends for bone formation in vitro[123]. } \\
\text { Protein adsorption[125]. } \\
\text { PLLA blends for vascular differentiation in vitro[124]. }\end{array}$ \\
\hline
\end{tabular}



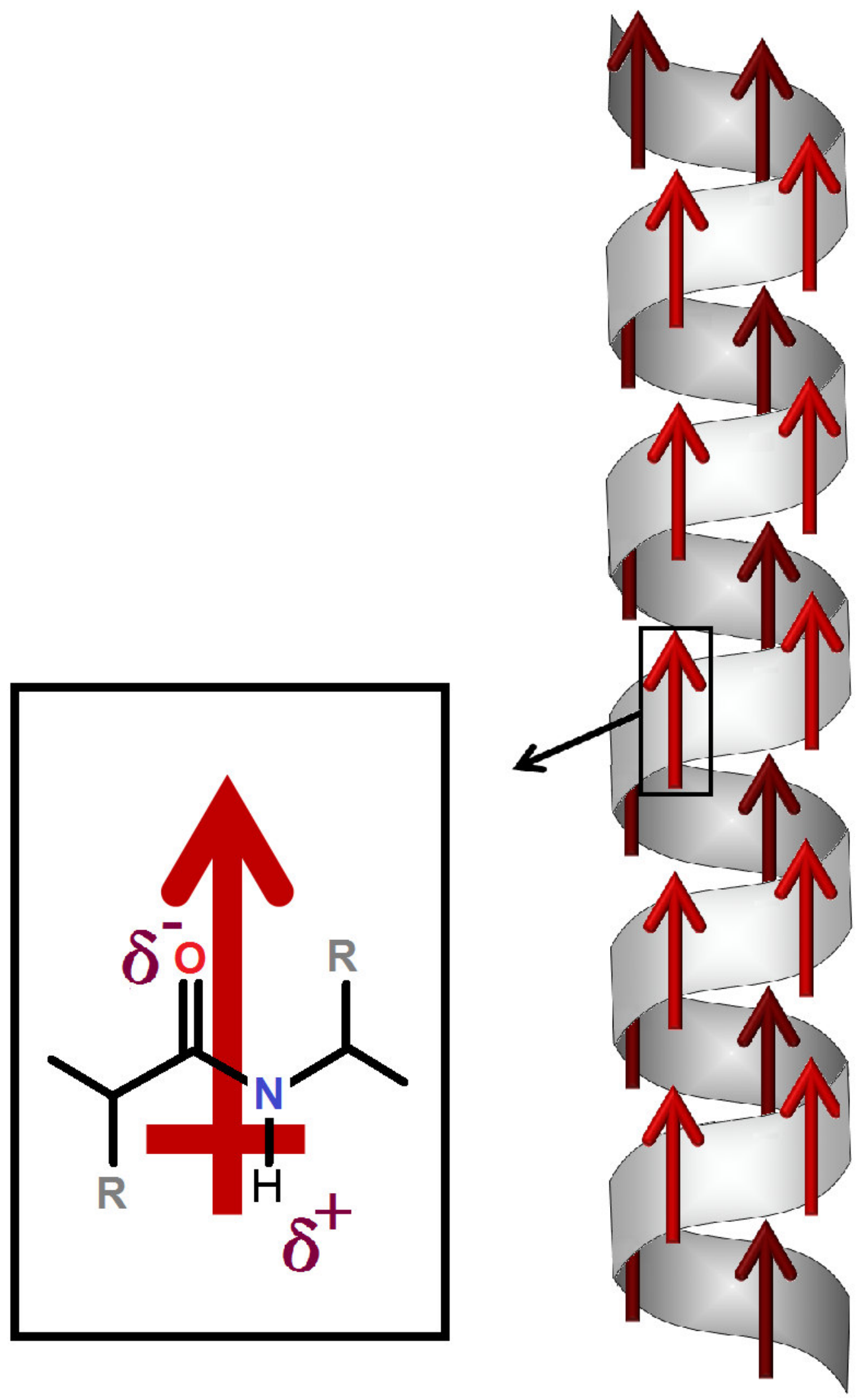
(a)

$400 \mathrm{~nm}$
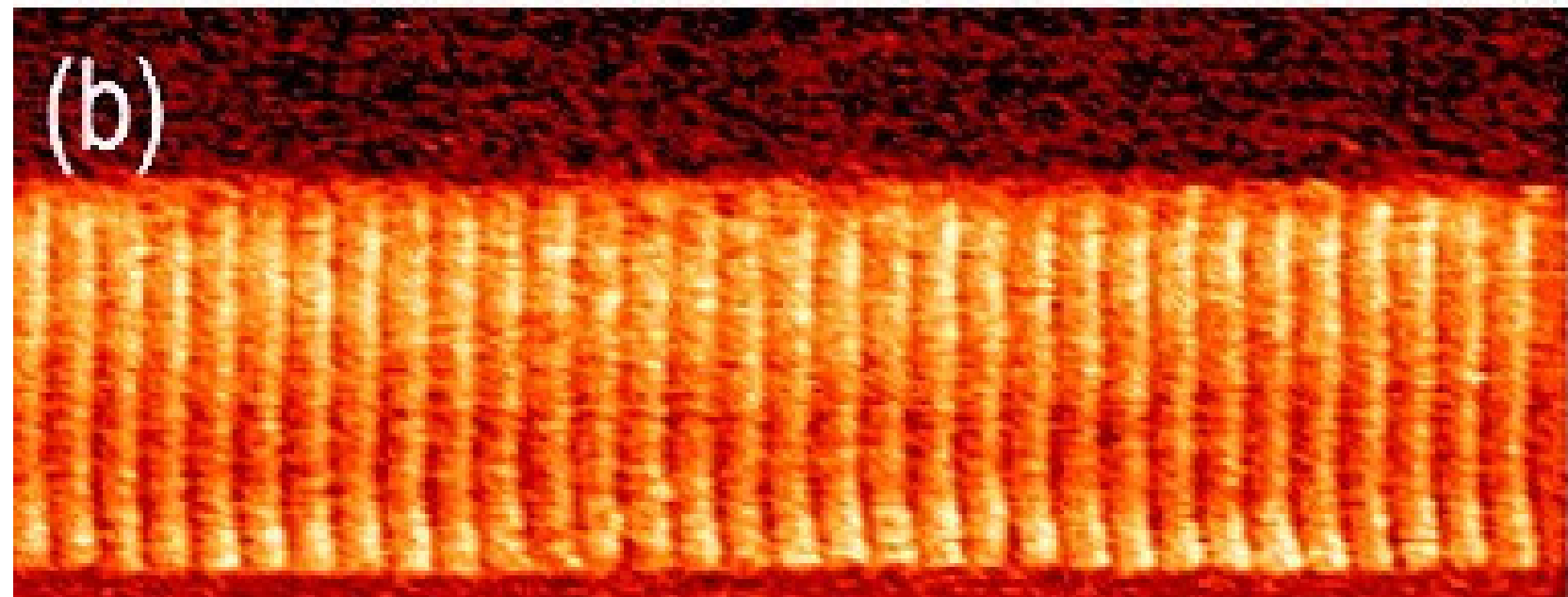

B 


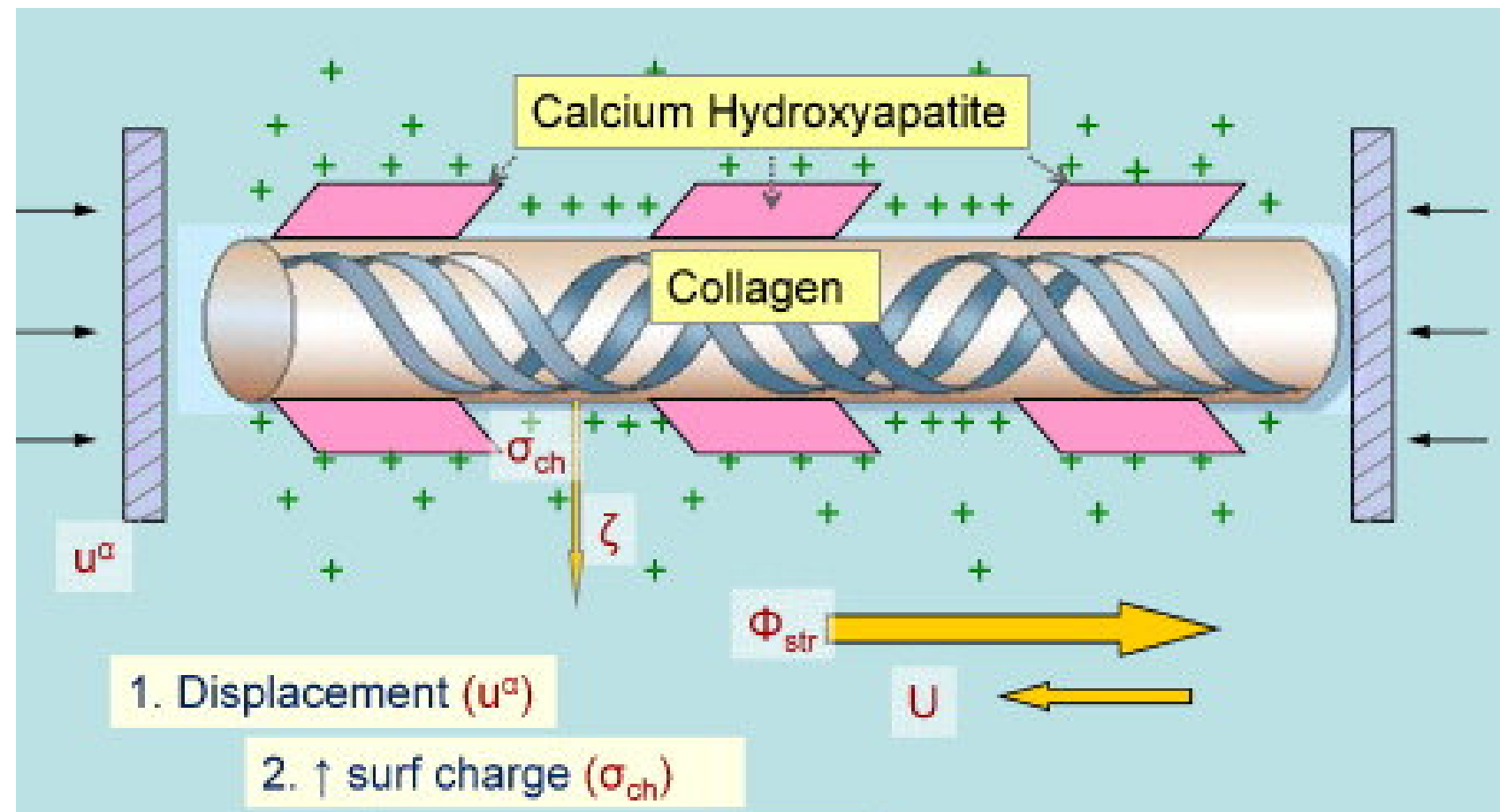

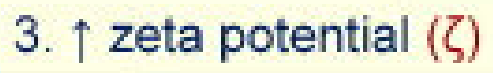

4. $\uparrow$ streaming potential $\left(\Phi_{\mathrm{st}}\right)$

5. $\uparrow$ electro-osmosis $(U)$

6. $\downarrow$ hydraulic permeability $(k)$

7. $\uparrow$ stress $(\sigma)$ 

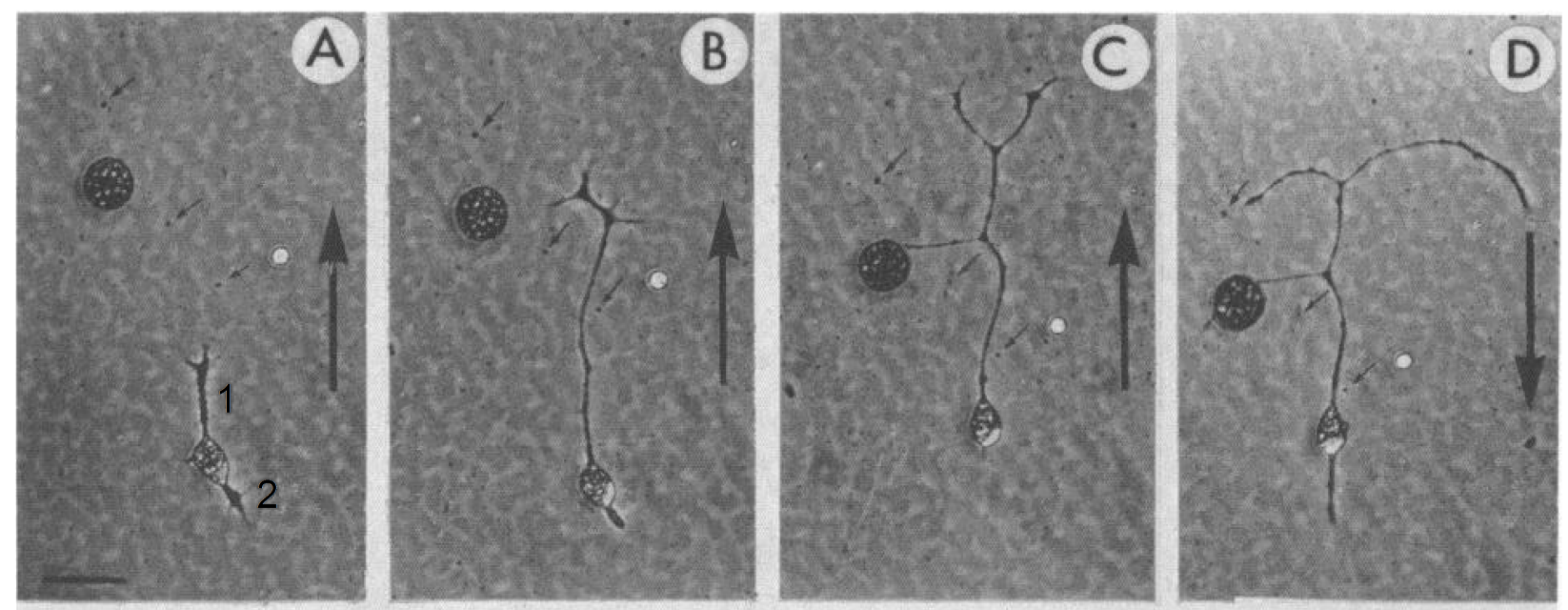

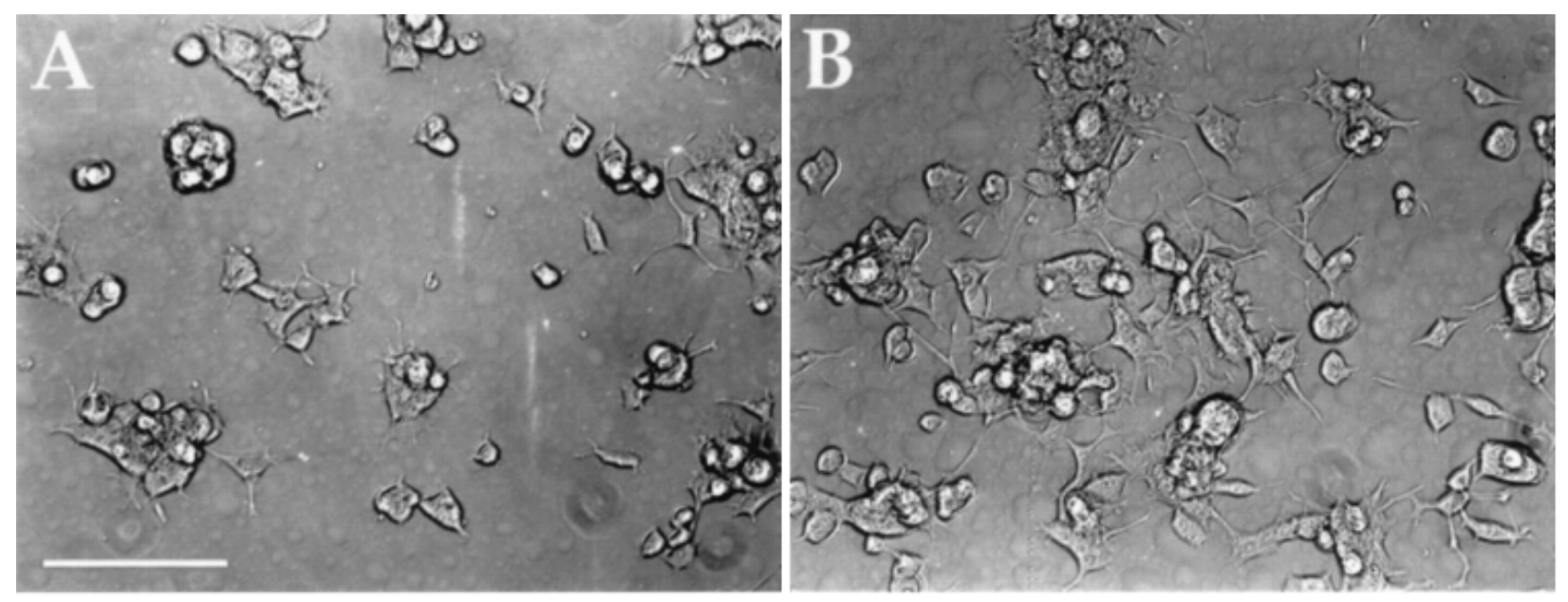
Cathode
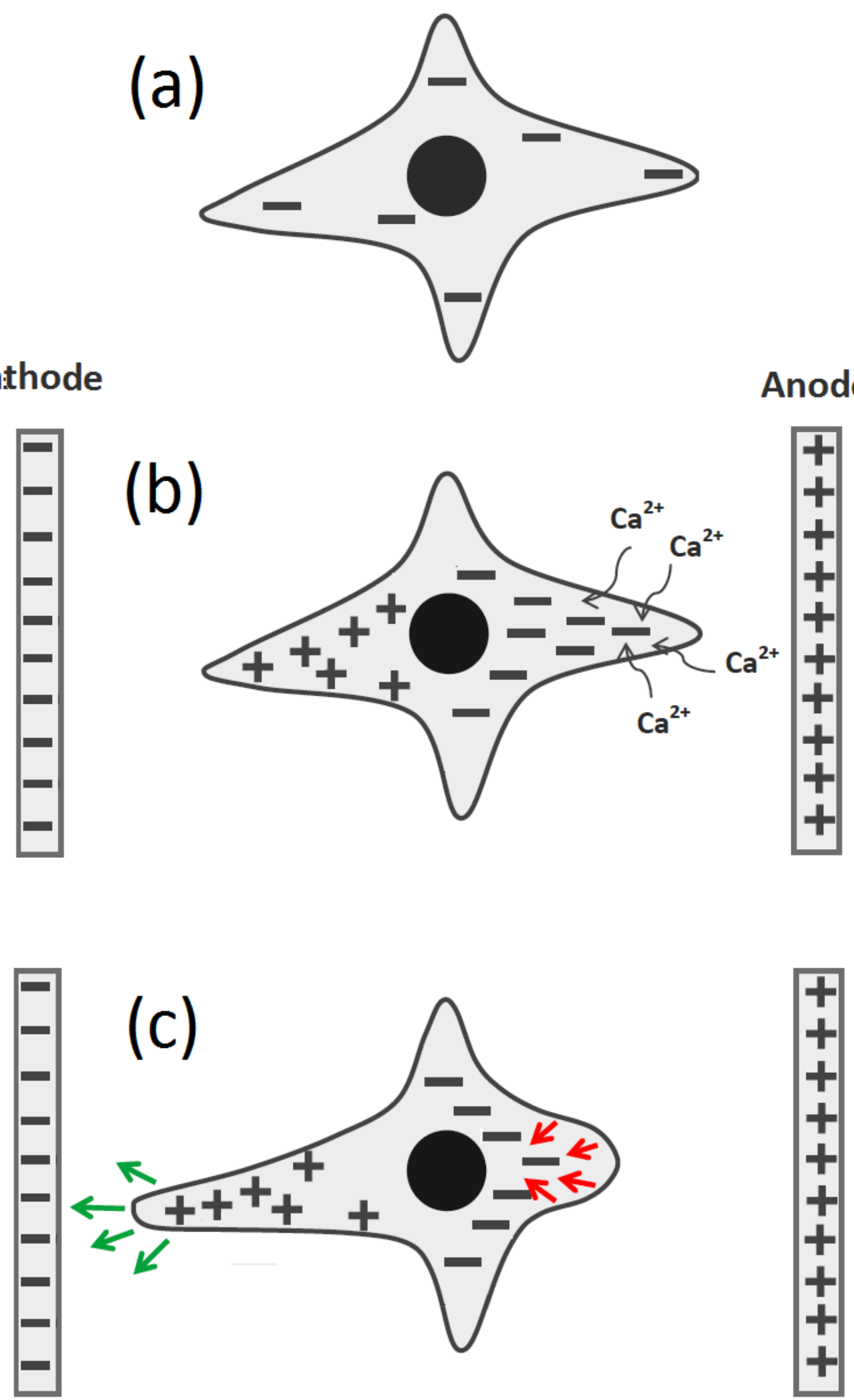

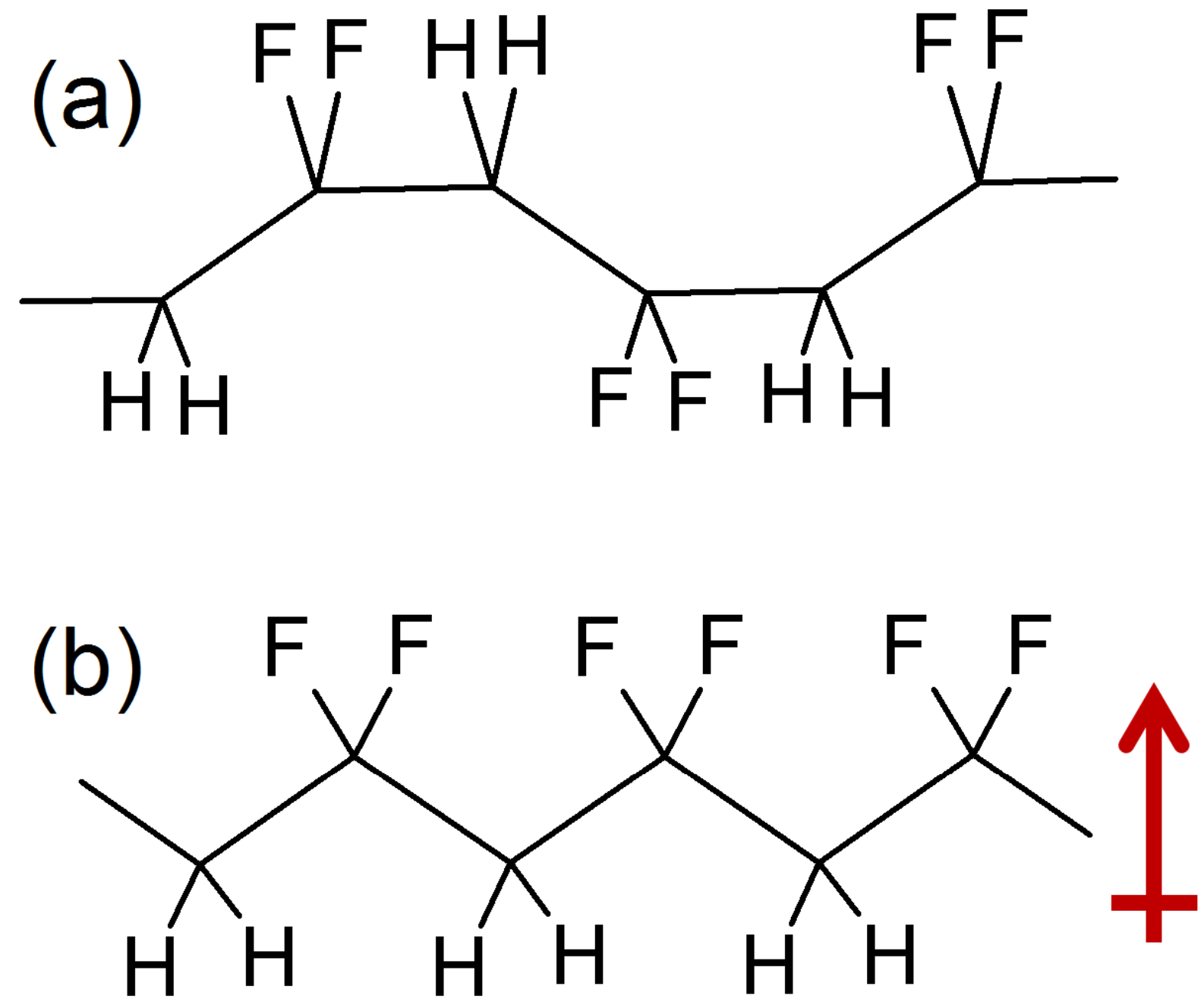

(c)

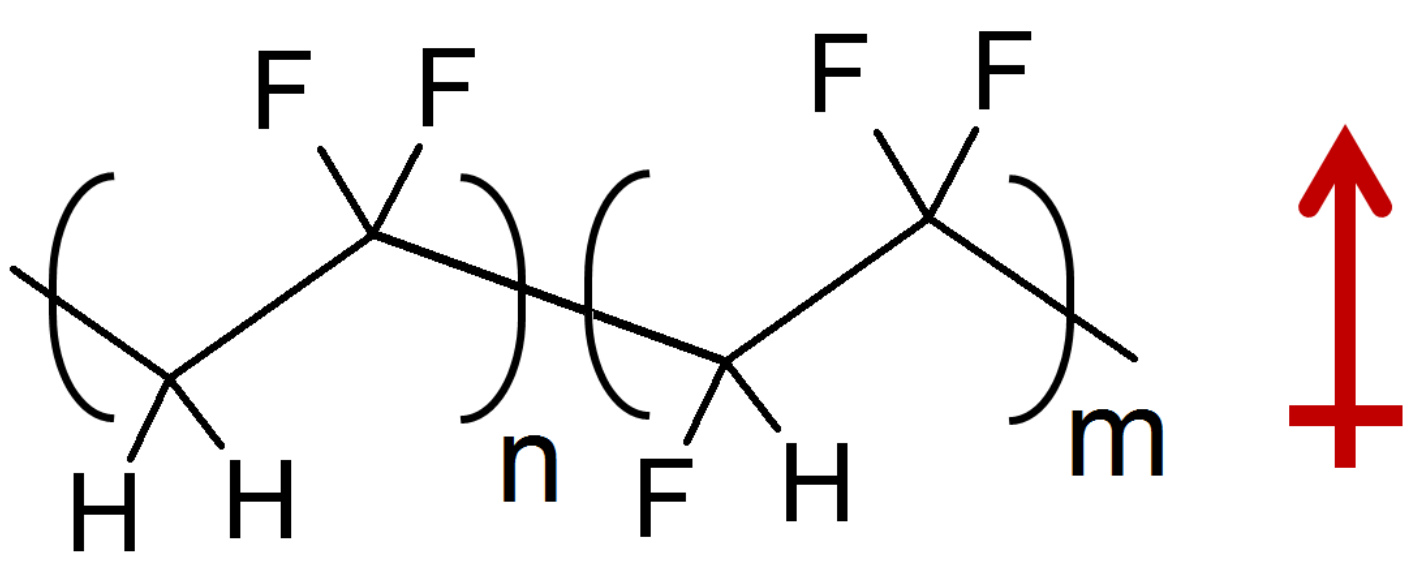



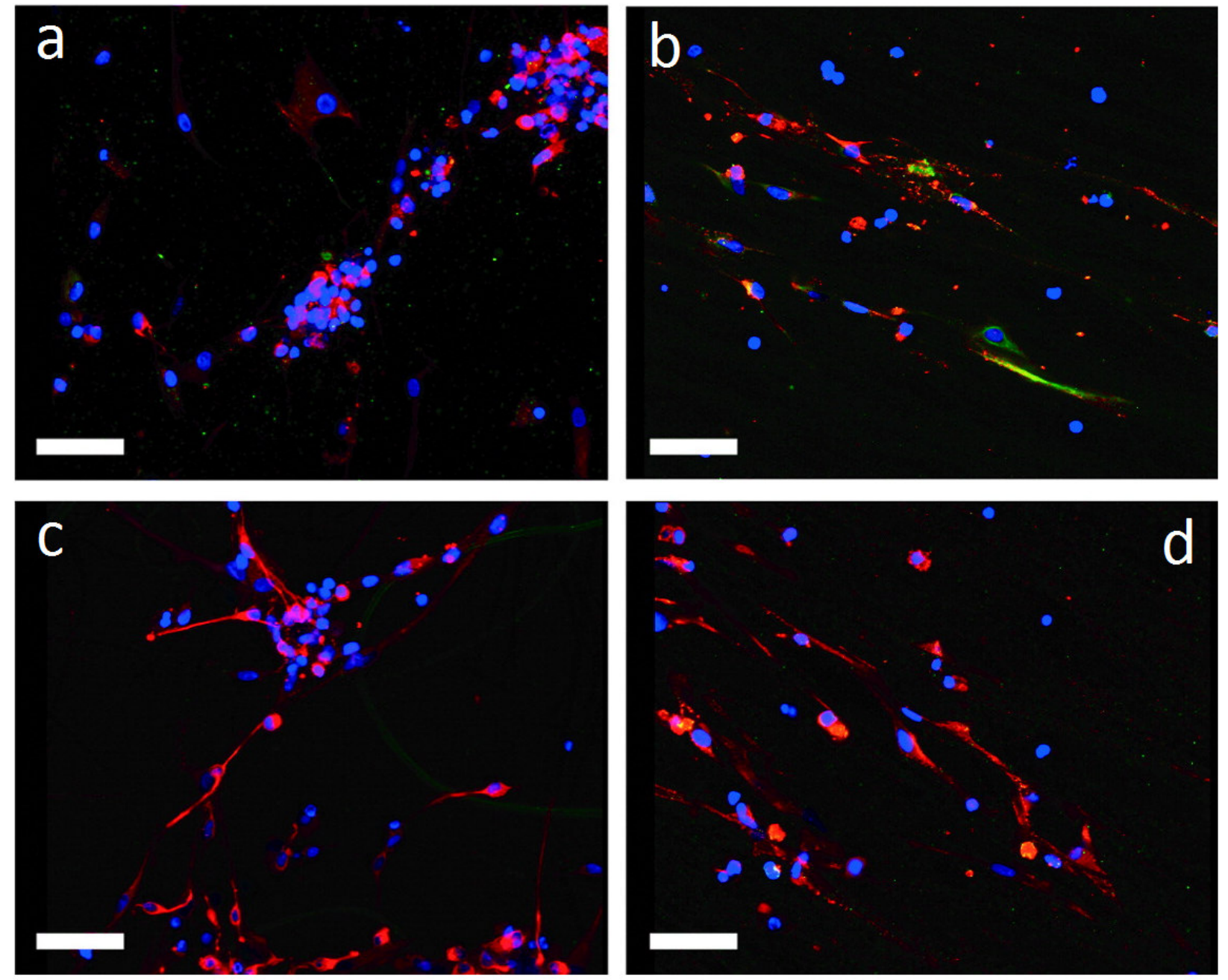


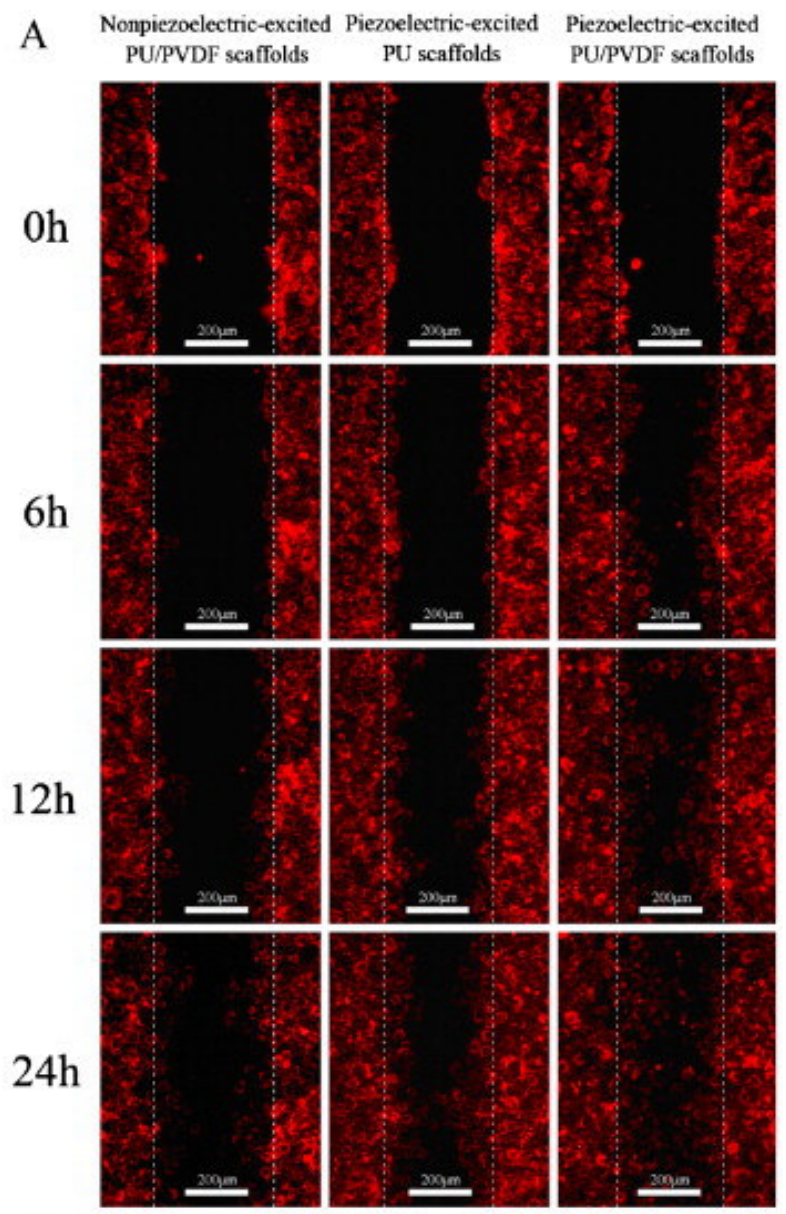

B

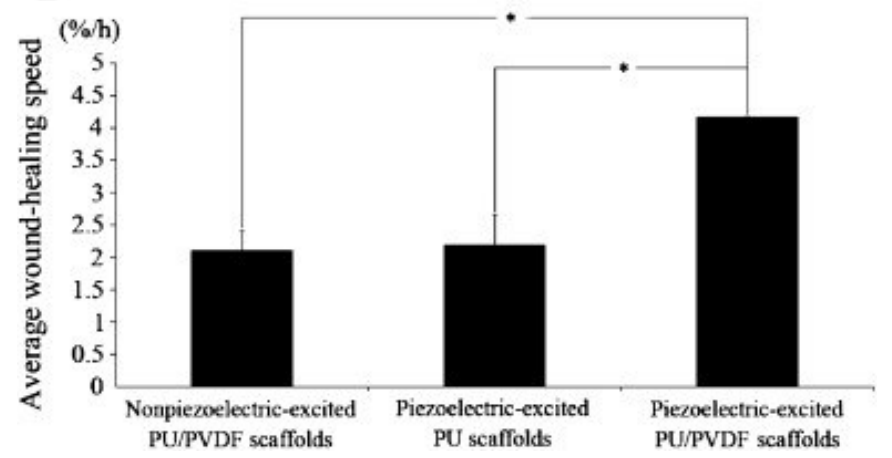




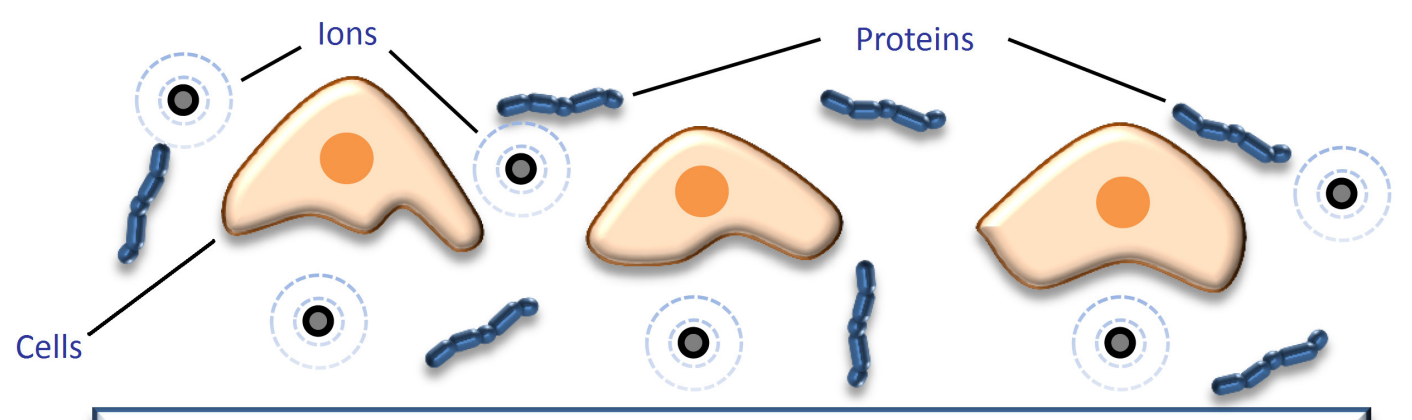

Piezoelectric Scaffold

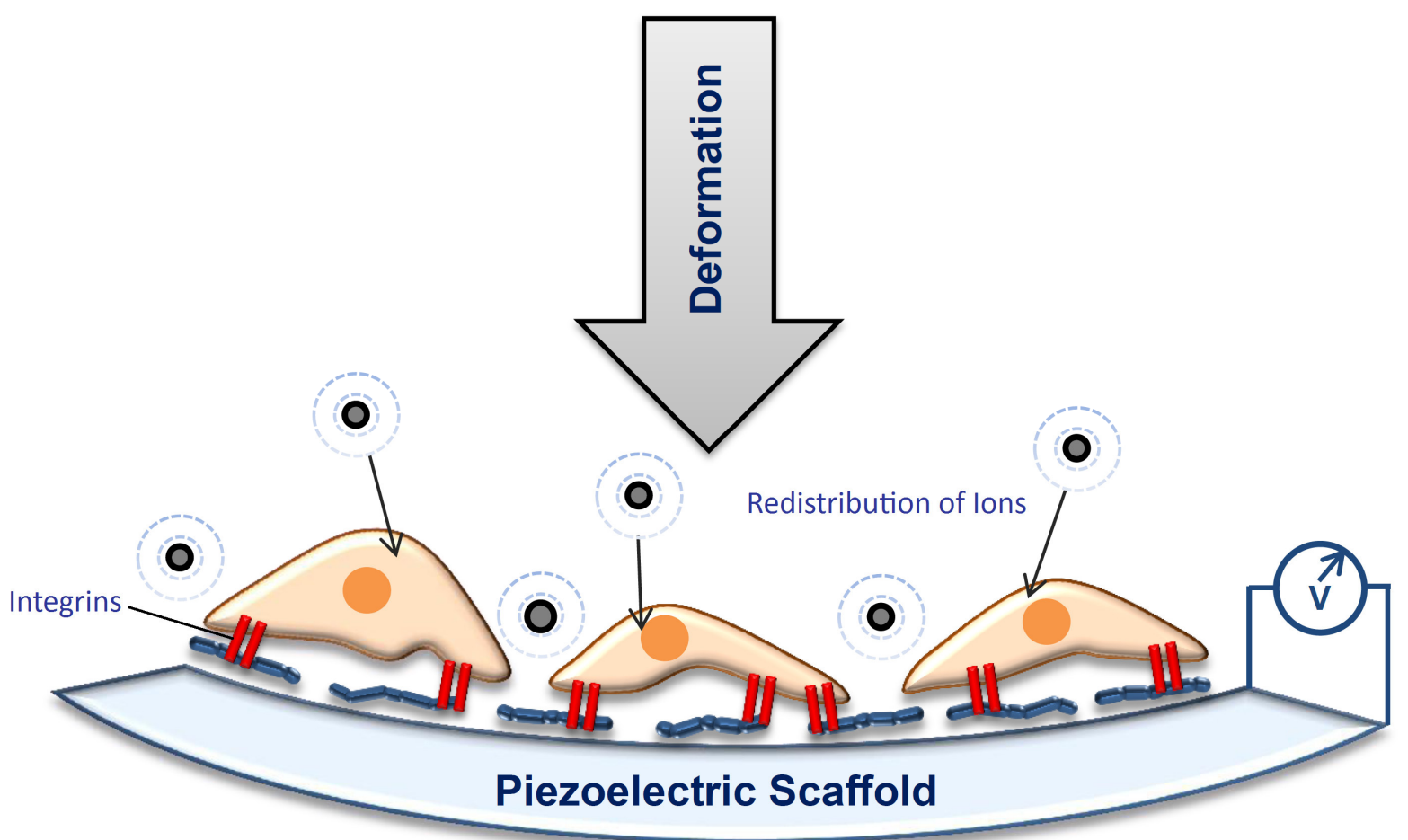

Graphical abstract 